\title{
Review \\ 3D Printing Polymeric Materials for Robots with Embedded Systems
}

\author{
Ray Noel Medina Delda ${ }^{1}$, Rex Balisalisa Basuel ${ }^{2,3}$, Rodel Peralta Hacla ${ }^{2,4}\left(\mathbb{D}\right.$, Dan William Carpiano Martinez ${ }^{5}$, \\ John-John Cabibihan ${ }^{6}$ and John Ryan Cortez Dizon ${ }^{1,7, *}$ (I)
}

1 DR3AM Center, Bataan Peninsula State University, City of Balanga 2100, Philippines; rnmdelda@gmail.com

2 Solid Freeform Fabrication Research Laboratory (SoFFReL), Urdaneta City Campus, Pangasinan State University, City of Urdaneta 2428, Philippines; rexbasuel@yahoo.com.ph (R.B.B.); rodel.hacla2011@gmail.com (R.P.H.)

3 Department of Computer Engineering, Urdaneta City Campus, College of Engineering and Architecture, Pangasinan State University, City of Urdaneta 2428, Philippines

4 Department of Electrical Engineering, Urdaneta City Campus, College of Engineering and Architecture, Pangasinan State University, City of Urdaneta 2428, Philippines

5 Department of Mechanical Engineering, College of Engineering and Architecture, Bataan Peninsula State University, City of Balanga 2100, Philippines; donemartz@gmail.com

6 Department of Mechanical and Industrial Engineering, Qatar University, Doha 2713, Qatar; john.cabibihan@qu.edu.qa

7 Department of Industrial Engineering, College of Engineering and Architecture, Bataan Peninsula State University, City of Balanga 2100, Philippines

* Correspondence: jrcdizon@bpsu.edu.ph

Citation: Delda, R.N.M.; Basuel, R.B.; Hacla, R.P.; Martinez, D.W.C.;

Cabibihan, J.-J.; Dizon, J.R.C. 3D Printing Polymeric Materials for Robots with Embedded Systems. Technologies 2021, 9, 82. https:// doi.org/10.3390/technologies 9040082

Academic Editors: Jeng-Ywan Jeng and Ajeet Kumar

Received: 28 September 2021

Accepted: 15 October 2021

Published: 2 November 2021

Publisher's Note: MDPI stays neutral with regard to jurisdictional claims in published maps and institutional affiliations.

Copyright: (c) 2021 by the authors. Licensee MDPI, Basel, Switzerland. This article is an open access article distributed under the terms and conditions of the Creative Commons Attribution (CC BY) license (https:// creativecommons.org/licenses/by/ $4.0 /)$.
Abstract: The fabrication of robots and their embedded systems is challenging due to the complexity of the interacting components. The integration of additive manufacturing (AM) to robotics has made advancements in robotics manufacturing through sophisticated and state-of-the-art AM technologies and materials. With the emergence of 3D printing, 3D printing materials are also being considered and engineered for specific applications. This study reviews different 3D printing materials for 3D printing embedded robotics. Materials such as polyethylene glycol diacrylate (PEGDA), acrylonitrile butadiene styrene (ABS), flexible photopolymers, silicone, and elastomer-based materials were found to be the most used 3D printing materials due to their suitability for robotic applications. This review paper revealed that the key areas requiring more research are material formulations for improved mechanical properties, cost, and the inclusion of materials for specific applications. Future perspectives are also provided.

Keywords: 3D printing; robotics; 3D printing materials; embedded systems; polymers

\section{Introduction}

Manufacturers commonly use conventional manufacturing processes for mass production (e.g., welding, casting, and injection molding). For highly customized and low volume manufacturing, a novel way of manufacturing known as additive manufacturing (AM) would be ideal. Additive manufacturing (or 3D printing) is the process of depositing materials layer by layer in order to produce the desired part, which is designed using computer-aided design (CAD) [1-5]. Three-dimensional printing can deliver increased freedom in design in terms of complex geometries [6]. It also minimizes the number of parts and reduces the total weight by altering parameters such as the infill density and infill pattern. In recent years, this technology has been used in various applications in electronics, water filtration, robotic systems, art, architecture, optics, biology, nanotechnology, aerospace, civil engineering, and tissue engineering [7-23].

Robotics, on the other hand, is referred to as the science and technology of robots. In the 1980s, it was also defined as the science that studies the intelligent connection between 
perception and action [24-26]. It is also known as the combination of mechanics, computer science, electronics, mathematics, physics, cybernetics, and artificial intelligence [20,21]. Robotics research continues to have a significant role in utilizing robots in inspection, medical treatment, clean-up, and sample collections in various environments [27,28]. Researchers have recently focused on developing and utilizing bio-inspired and biomimetic mechanisms achieved through additive manufacturing technologies [29]. Although soft structures can be created, separately manufactured actuators must be integrated to form a functioning soft system. These actuators can be thermally activated joints, piezoelectric fibers [30], shape memory alloys [31], and electric motors [32].

Mechanical robots are made of hard and stiff materials. These properties limit their capability to deform elastically and adapt in terms of shape. Although they tend to be robust, these rigid robots do not exhibit the ability to be a multifunctional system [33]. Meanwhile, soft robots are hailed as the next generation of robots as they are elastic and soft. They can be utilized safely and steer through constrained environments. A soft robot must possess an elastic deformability and steering capability similar to a small octopus and a mouse in order to enter narrow spaces without inducing stress concentrations on the surrounding (or sub-) components [13,34,35].

The developments in additive manufacturing can be combined with the technology of soft robotics. This combination consolidates compliant machinery and actuators to enable movement and equal force distribution. The actuation, compliance, and complex motions make 3D printed soft robots ideal alternatives for applications mainly in the biomedical engineering field, which favors the interface of machines and humans as it reduces the stress concentration achieved through conformal contacts and multiple degrees of freedom at low impact forces [28,36-38].

To limit the scope of this review, it is focused on 3D printing polymer materials for soft and hard robotic applications that involve embedded systems. Generally, robots are manufactured using traditional manufacturing methods that utilize molds to produce parts $[3,18,39]$. The significant trend towards combining AM technology and robotics leads to the idea that 3D printing must be applied to avoid the use of molds and to further maximize the utilization of materials, which will eventually lead to enhanced soft and embedded robotic systems [36].

Taking into account the lack of data on 3D printing materials for robots with embedded systems, this review explores answers to the following research questions:

1. What are the 3D-printable materials for robots with embedded systems?

2. What are the limitations of the materials in terms of applications and suitability?

3. How do we fully incorporate $3 \mathrm{D}$ printing with robots that enable improvement in terms of mobility and performance?

This review investigates the recently developed 3D printing polymers suitable for robotic applications produced by the industry and employed by different research groups. At the moment, there are still minimal review papers that focus on the suitability of $3 \mathrm{D}$ printing polymers for soft and hard robotic applications, especially those with embedded systems.

\section{Methodology}

Relevant information was gathered based on different factors and parameters such as the application in robotics and the printability of the materials. Keyword search was used in online scientific journal platforms such as Science Direct and Scopus. The following key terms were used for the search: "3D printing, additive manufacturing, AND robots" or "embedded systems, additive manufacturing, AND robots" or "3D printing materials, additive manufacturing, AND robots" or "3D printing, additive manufacturing, AND embedded systems". The evaluation criteria for the inclusion of the paper was based on how it could be applied in robotic applications, how it was 3D printed, and how it was blended to be used for robotics. Information was gathered from publications from the year 2000 to 2020. 
Initial scanning of the research articles was performed. All of the papers or articles that contained the mentioned keywords were gathered from the research databases. Relevant papers and articles that were scanned and deemed not relevant were eliminated. An in-depth analysis was then carried out on the final list of included papers. Based on the analysis, some papers could be categorized as articles focused on (a) 3D printed robots and (b) 3D printing materials for robots with embedded systems installed. Articles under Category A provided an essential foundation for the review as they tackled soft and hard robots, whereas articles under Category B provided insight on the materials used for highly complex robots that possessed embedded systems. Figure 1 shows a visual flow of the steps, keywords, and databases used in the literature search as the method.

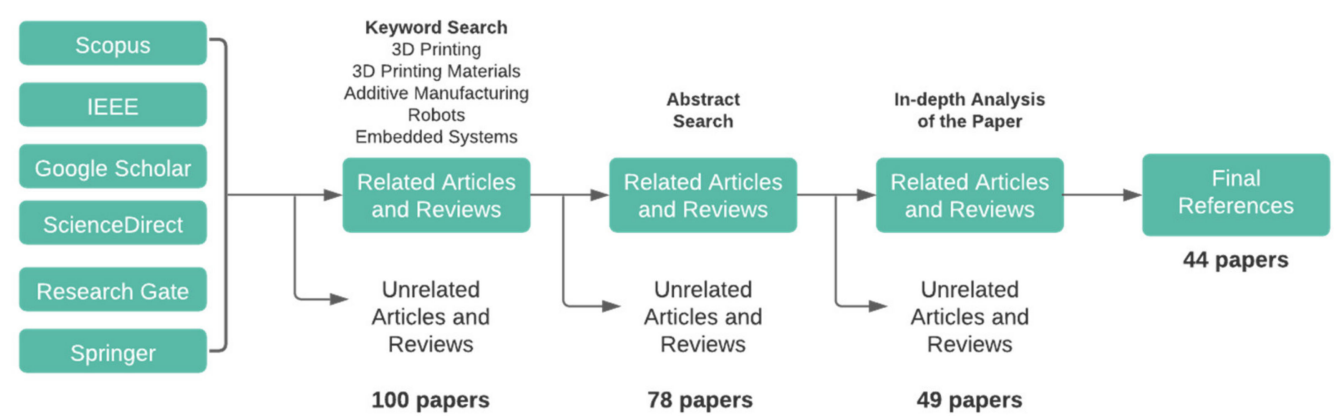

Figure 1. Flowchart showing the process used for the literature search.

\section{Taxonomy of 3D Printing Polymerics Materials for Robots with Embedded Systems}

Three-dimensional printing technologies are known to efficiently produce complex and intricate parts $[3,4,14]$. In some cases, robotic parts require small and hollowed areas to embed materials and components ranging from alloys to motors [7]. Robots are typically manufactured using conventional fabrication methods that suffer from design limits and part complexity issues [39-42]. Aside from printing hollow structures, the 3D printing process reduces the design constraints and increases the design complexity with the use of computers [24,25].

Robotics and 3D printing are technologies that are gradually being incorporated for manufacturing, research, and development purposes. To date, there is still no study that compiles the 3D printing materials and 3D printing technologies that are appropriate for specific robotics applications. This study provides a taxonomy of 3D printing materials for embedded robotics; researchers and roboticists can review 3D printing materials and compare their advantages and disadvantages based on robotic applications. Polymer materials are classified into three types, as shown in Figure 2 [43].

Thermoplastic polymer molecules possess weak intermolecular forces. Thus, the material softens once exposed to high temperatures and returns to its original state once it is cooled. Amorphous thermoplastic polymers are rigid. They are flexible or rubber-like just above the glass transition temperature $(\mathrm{Tg})$ and have a glass-like behavior below them. As the temperature increases above the glass transition temperature, the polymer becomes soft and becomes a viscous fluid. A (theoretical) 100\% crystalline thermoplastic would have a distinct melting point (Tm) at which point it transforms from solid to liquid, but would not demonstrate any perceptible $\mathrm{Tg}$. Crystalline polymers are never fully crystalline because most crystalline polymers have amorphous regions. Thermoplastics can be used in many applications as they can be formed into any shape [44]. Thermoplastics such as acrylonitrile butadiene styrene (ABS) and polylactic acid (PLA) are two of the most common 3D printing materials for robotic part production. 


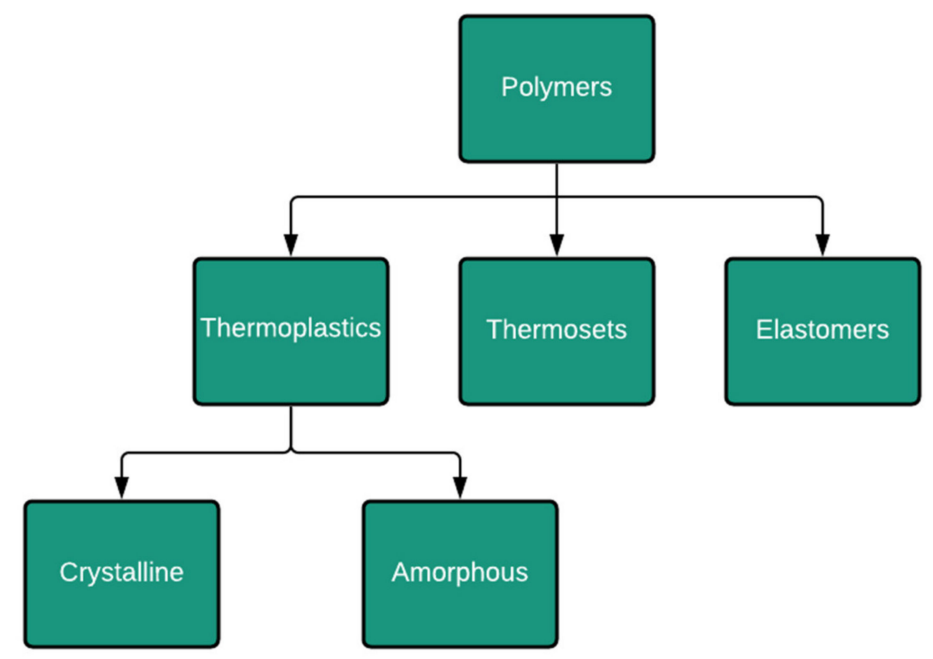

Figure 2. The taxonomic structure of polymers showing the different classification of polymer materials [43]. Licensed under Creative Commons.

Thermosets, however, cannot reshape compared in the same way as thermoplastics due to their dimensional networks of polymers, where a high degree of crosslinking between its polymer chains exists. This high degree of crosslinking inhibits chain motions, leading to the material's rigidity [44-46]. Thermosets are usually used in 3D printing as materials for stereolithography (SLA), digital light processing (DLP), and direct ink writing (DIW) printing. Examples of thermosets include epoxies, amino resins, phenolics, and many others.

Lastly, elastomers are rubbery polymers. They can stretch to twice their original size and return to their original dimensions once released. Elastomers are crosslinked but still possess low crosslink densities. Their chains are free to move, but movement permanency to each other is diminished by crosslinks [43,47]. To cite an example, Hamidi et al. [48] discussed 3D-printed elastomers for robotic applications with carbohydrates or sugars as the support materials.

\section{Overview of Additive Manufacturing}

As per the ASTM international standards, AM technology is a technique of adding materials that work based on addition rather than reduction. However, according to Singh et al. [17-23,49], AM is not a technique but a principle. AM is the most widely used name for this principle, but it is also synonymous with freeform fabrication, rapid prototyping, and rapid manufacturing $[1,18,20,22,23,50]$.

Figure 3 shows the process flow for additive manufacturing [10]. The process starts with modeling and preparing the desired design, which will be converted to .stl, .obj, or .amf format before slicing for 3D printing. The 3D model will then be converted into G-code in the slicing software or AM system, usually dedicated to a 3D printer. The model is sliced into layers, and the printing parameters such as layer thickness, printing speed, and infill density are modified during the slicing process. The G-code will then be uploaded or transferred to the $3 \mathrm{D}$ printer to initiate the fabrication of the design. The printed design may be subjected to post-processing to remove imperfections and to cure the design. This technique will also help with preparing the design for its intended application [10].

A significant number of AM technologies are already commercially available in the market, and they differ in the layer creation, post-curing process, principle of operation, and the type of material used in printing. These AM technologies cater to different applications depending on the needs of society and the industry [51,52]. A brief discussion on the different technologies is presented to provide the reader with a good background on their operating principles. Based on ISO or ASTM 52900 [53], additive manufacturing has been 
categorized into seven processes, as shown in Table 1 [1,19,22,23]; also included in the table are the common types of materials used, where some can be used in robotics applications.

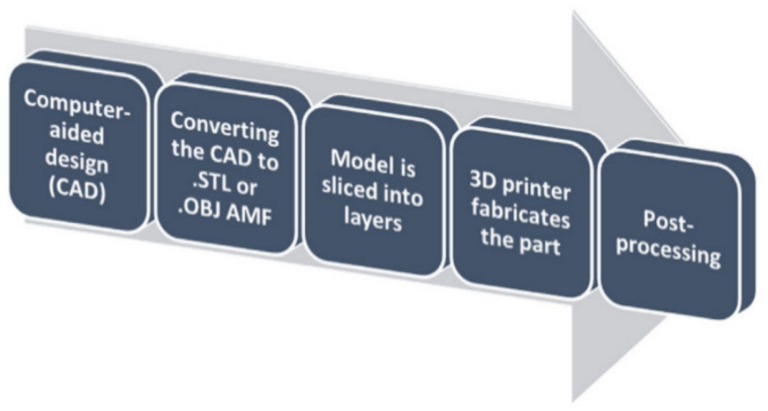

Figure 3. Process flow of the 3D printing process [10]. Reprinted with permission from ref. [10]. Copyright 2021 Elsevier.

Table 1. Classification of AM technology according to its process [4,19,22,23].

\begin{tabular}{|c|c|c|c|c|c|}
\hline Process & Technology & $\begin{array}{l}\text { Layer Creation } \\
\text { Technique }\end{array}$ & Polymerization Process & Typical Manufacturers & Materials \\
\hline \multirow{5}{*}{ Vat Polymerization } & Stereolithography (SLA) & UV light scanning & Cured with UV light & $\begin{array}{l}\text { Formlabs, 3D Systems, } \\
\text { and DWS }\end{array}$ & \multirow{3}{*}{$\begin{array}{l}\text { Standard and castable } \\
\text { resins }\end{array}$} \\
\hline & $\begin{array}{l}\text { Digital light processing } \\
\text { (DLP) }\end{array}$ & Digital light projection & Cured with UV light & $\begin{array}{l}\text { B9 Creator and } \\
\text { MoonRay }\end{array}$ & \\
\hline & Continuous DLP & Digital light projection & $\begin{array}{l}\text { Cured with LED and } \\
\text { oxygen }\end{array}$ & $\begin{array}{l}\text { Carbon3D and } \\
\text { EnvisionTEC }\end{array}$ & \\
\hline & $\begin{array}{l}\text { Continuous liquid } \\
\text { interface production } \\
\text { (CLIP) [28-30] }\end{array}$ & $\begin{array}{l}\text { Digital light projection, } \\
\text { oxygen-permeable } \\
\text { optics, and } \\
\text { programmable liquid } \\
\text { resins [28-30] }\end{array}$ & Cured by a UV light & Carbon & $\begin{array}{l}\text { Polyurethane } \\
\text { (elastomeric, flexible, } \\
\text { and rigid), epoxy, UMA } \\
\text { 90, silicone, and } \\
\text { urethane methacrylate } \\
\text { [28-30] }\end{array}$ \\
\hline & $\begin{array}{l}\text { Daylight polymer } \\
\text { printing (DPP) }\end{array}$ & $\begin{array}{l}\text { Uses light from LCD } \\
\text { screens }\end{array}$ & $\begin{array}{l}\text { Cured by liquid crystal } \\
\text { display (LCD) and } \\
\text { daylight polymer }\end{array}$ & Photocentric & Daylight resins \\
\hline \multirow[b]{2}{*}{ Powder Bed Fusion } & Multi jet fusion & Ink fusing agent & $\begin{array}{l}\text { Fused with agent and } \\
\text { energy }\end{array}$ & $\mathrm{HP}$ & Nylon \\
\hline & $\begin{array}{l}\text { Selective laser sintering } \\
\text { (SLS) }\end{array}$ & Laser scanning & Fused with laser & Stratasys & $\begin{array}{l}\text { Polyether etherketone } \\
\text { (PEEK), thermoplastic } \\
\text { olyurethane (TPU), and } \\
\text { nylon }\end{array}$ \\
\hline Material Extrusion & $\begin{array}{l}\text { Fused deposition } \\
\text { modeling (FDM) }\end{array}$ & $\begin{array}{l}\text { Continuous extrusion } \\
\text { and deposition }\end{array}$ & - & $\begin{array}{l}\text { Stratasys, Ultimaker, } \\
\text { MakerBot, and } \\
\text { Markforged }\end{array}$ & $\begin{array}{l}\text { ABS, PLA, } \\
\text { polycarbonate (PC), } \\
\text { nylon, and ULTEM }\end{array}$ \\
\hline \multirow{3}{*}{ Material Jetting } & Material jet fusion (MJF) & $\begin{array}{l}\text { Dispenses } \\
\text { photopolymer in a } \\
\text { printhead }\end{array}$ & Cured with UV light & $\begin{array}{l}\text { Stratasys (Polyjet) and } \\
\text { 3D Systems (MultiJet) }\end{array}$ & $\begin{array}{l}\text { Rubber-like and } \\
\text { ABS-like (multicolor) }\end{array}$ \\
\hline & Drop on demand (DOD) & $\begin{array}{l}\text { Dispense viscous } \\
\text { liquids and create } \\
\text { wax-like parts }\end{array}$ & Cured with UV light & Solidscape & Wax-like \\
\hline & Polyjet & $\begin{array}{l}\text { Jetting ultra-thin layers } \\
\text { in a build tray }\end{array}$ & Cured by UV light & Objet (Stratasys) & ABS \\
\hline Binder Jetting & Binder jetting & $\begin{array}{l}\text { Deposits binding } \\
\text { adhesive agent }\end{array}$ & $\begin{array}{l}\text { Joined with a bonding } \\
\text { agent }\end{array}$ & $\begin{array}{l}\text { 3D Systems and Voxeljet } \\
\text { ExOne }\end{array}$ & $\begin{array}{l}\text { Silica sand and PMMA } \\
\text { particle material }\end{array}$ \\
\hline Sheet Lamination & $\begin{array}{l}\text { Laminated object } \\
\text { manufacturing (LOM) }\end{array}$ & $\begin{array}{l}\text { Feeding and binding of } \\
\text { sheets with adhesives }\end{array}$ & $\begin{array}{l}\text { Peeling and removal of } \\
\text { excess material }\end{array}$ & $\begin{array}{l}\text { Helisys and Cubic } \\
\text { Technologies }\end{array}$ & Plastics \\
\hline $\begin{array}{l}\text { Direct Energy } \\
\text { Deposition }\end{array}$ & & & & $\begin{array}{l}\text { BeAM, Optomec, } \\
\text { Trumpf, and FormAlloy }\end{array}$ & Metal \\
\hline
\end{tabular}

\subsection{Vat Polymerization}

This AM process uses a liquid photopolymer placed into a tank to be selectively cured by a laser or an ultraviolet (UV) light through photopolymerization [51,54]. Photopolymerization is the process that is in control of making the thin layer of liquid resin 
solidify when exposed to UV light. One of the earliest types of AM technology using vat photopolymerization is stereolithography [55]. An epoxy or acrylic is one of the typical photocurable resins used in this technology [1].

\subsection{Material Jetting}

This AM process is analogous to ink-jet printing in a manner that the ink droplets are transferred from the liquid channel onto the paper substrate [54]. These ink droplets are directly deposited to the printhead, which will be solidified through UV light exposure to create the 3D object. These droplets are often made of photopolymers mixed with wax or any secondary material used during the build process for the support structures [56]. Some of the standard technologies related to this process include multi-jet modeling, nanoparticle jetting, and drop-on-demand [18-28].

\subsection{Material Extrusion}

This AM process can be compared to how a glue gun operates. The glue stick is pushed out and extruded through its nozzle. Similarly, this AM process uses thermoplastic materials, commonly referred to as filament (in some cases pellets), which are fed onto the nozzle until it melts. The material is then deposited to the platform to form a solid object layer by layer [1,21-23]. Fused deposition modelling (FDM) is one of the most commonly used AM technologies utilizing the extrusion process. Direct ink writing is also considered to be under this category $[1,14,53,55,57-59]$.

\subsection{Powder Bed Fusion}

This AM method uses a laser as a thermal source to fuse layers of powder particles to another powder layer. Sintering and melting are mainly the binding mechanisms of this AM process. Sintering works by only partially melting the powder, where a solidstate particle can be fused at the surface only. Melting, on the other hand, means that the particles are fully melted (in liquid-state) and can be fused [39,47]. Some of the technologies related to this process include electron beam melting (EBM), selective laser sintering (SLS), selective laser melting (SLM), and direct metal laser sintering (DMLS) $[44,49]$.

\subsection{Binder Jetting}

This method uses a bond agent to individually add powdered particles to create a 3D object [56]. This bond agent is dropped from the printhead, coating a powder on the build platform to form the object to each layer. This step is continuously performed on each layer until a completely solid object is formed $[39,47,60]$. AM technologies related to this process include powder bed and inkjet head (PBIH), plaster-based 3D printing (PP), and color jet printing (CJP) [49,54].

\subsection{Direct Energy Deposition (DED)}

This AM process uses a high-powered laser for the metal powders to melt, in which these metal powders have a direct effect on the resolution of the printed object [54]. This method is different from the powder bed fusion in the way that the laser is emphasized on a metal powder deposited onto the surface of the metal powder layer. DED resolution relies on its energy source, which has a higher energy source, and would result in a higher and better-printed output $[50,56,61]$. Common technologies using this process include laser engineered net shaping (LENS) and electron beam additive manufacturing (EBAM).

\subsection{Sheet Lamination}

This AM process uses thin sheets of plastics or metals joined together using adhesives to create an object. Layer by layer, a new thin sheet is placed repeatedly on top of the previous layers until the part is completed. It uses a laser or knife to cut or refine the edges of the desired object $[49,51,61]$. One of the widely used AM technologies under this process is laminated object manufacturing (LOM). 
To compare the listed 3D printing processes, SLA can produce parts with extremely high dimensional accuracy and intricate details. SLA printed parts are ideal for visual prototypes due to their very smooth surface finish; however, they will deteriorate over time when exposed to sunlight. Material jetting, like SLA, has the potential for a high accuracy and surface finish, while being a relatively slow build process. Binder jetting prints at high speeds, making it fast to build, but it has a poor surface finish due to its limited accuracy. DLP allows for the simultaneous production of complex shapes and sizes with a high precision but limited material range. Compared with other polymer 3D printing techniques, SLS can print parts at higher speeds and with relatively higher heat and chemical resistance; however, its accuracy is limited due to the size of the powder particle. On the other hand, FDM has the lowest dimensional accuracy and resolution, making it unsuitable for intricate parts. DED could build large parts with a high production flexibility and print multi-materials at a high cost. To achieve a smooth finish, DED, like other technologies, requires post-processing. Furthermore, compared with other AM technologies, LOM can build large parts faster and at a lower cost, but with less accuracy and inconsistent quality.

\section{Overview of Robotics and Applications}

Robotics employs a multi-disciplinary approach that involves designing, developing, operating, and utilizing robots [62,63]. Robots can be programmable and perform complex human tasks [64-68]. For a robot to function, it must have the power to energize its components, usually through a direct current source such as $5 \mathrm{~V}, 9 \mathrm{~V}$, and $12 \mathrm{~V}$. Occasionally, it goes higher than it should, depending on the design and applications [69]. Sensors, such as heat, pressure, temperature, IR waves, and radio waves, are typically attached to the robot to interact, provide, and receive feedback with the real world [70]. Some robots also have sensors for vision, taste, smell, and touch. A robot can move via actuators such as DC motors, servo motors, and stepper motors [71], and others have mechanical arms and legs [72-74]. Data coming from the sensors, whether analog or digital, are processed through a microcontroller. The microcontroller then analyzes the data and makes its own decision relevant to the given condition [75]. Figure 4 shows the key components of robotics. Applications of robots include industrial robots [76-81], aerospace [81-84], drones [80,82-84], military [80,85,86], agriculture [80,87], car manufacturing robots [76-81], education $[80,88,89]$, hobby $[80,90]$ and competition robots $[80,90]$, medical robots $[80,85,86]$, and commercial entertainment robots $[80,82,90,91]$.

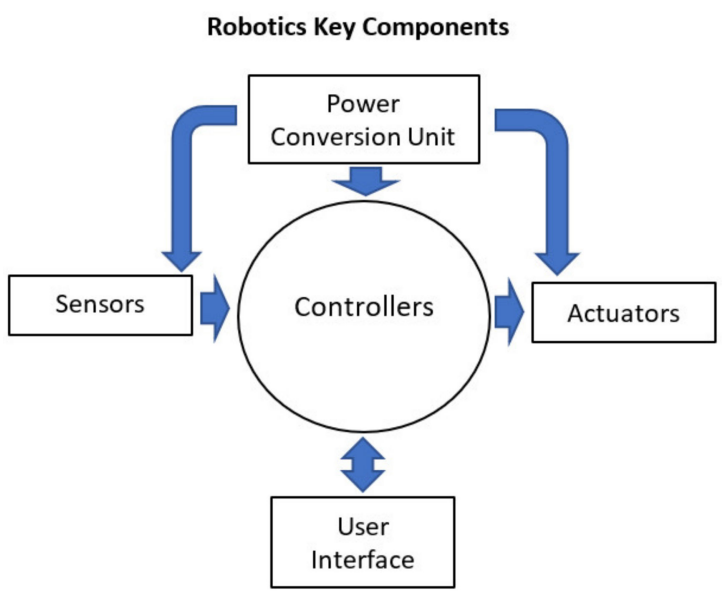

Figure 4. Key components of a robot. The figure shows the components used by robots to fulfill their purposes, such as interaction with their environment [92].

\subsection{Hard Robots}

Hard robots are made of stiff materials like hard plastics and metals. Typically, hard robots consist of sensors, actuators, mechanical structures, and motion transmission, 
and interface with their controller to meet the strict requirements of manufacturing and industrial automation [63].

\subsection{Soft Robotics}

Soft robots are used in areas where rigid robots are not feasible, such as non-invasive surgical procedures, assistive devices, prostheses, or artificial organs. Soft robots are made from soft, flexible, stretchable materials like hydrogels, silicones, or polyurethanes. They also require soft sensors and actuators that are embedded into the robot body [35,93-96].

\subsection{Embedded Systems}

Robots have various vital components to fulfill their purpose and perform various activities, as shown in Figure 4. They use sensors, actuators, and software to safely analyze, react, and perform in their current environmental setting through a set of programmed goals. In every robot, there is an embedded system that connects various subsystems within [97]. The sensor is one of the most crucial parts of robots to control their actions, specifically to provide information for movements about task-relevant discrete events [35]. Considering that robots can perform different tasks through embedded systems, there is a growing demand for these devices in different fields, such as prosthetics (medical application), where microchips translate muscle movements into responses. Three-dimensional printing materials that can function according to the commands of the embedded systems will further improve the performance of robots and introduce more applications in various research areas and industries [98].

An embedded system is made up of hardware and software that are used to perform a specific task. It can be programmable, depending on the functionality. Hardware is comprised of sensors and actuators controlled by a microcontroller or HDL components (Hardware Description Language). Robotics is just one of the many different applications of embedded systems, and other applications include home appliances, security, telecommunication, aerospace, automobiles, and other embedded systems projects [58,62,63,98-101].

There are also drawbacks of 3D printing technology, which should probably be considered before using this process.

Limited materials-Plastics and metals are materials that are commonly used in 3D printing to create models. Over time, material options are expanding as the demand grows, but it is still far compared with the materials used in traditional manufacturing. Plastics are now the most widely used 3D printing material, especially in prototyping, as they are inexpensive and easy to manage due to their lower melting point. Fused deposition modeling (FDM) and stereolithography (SLA) are the two main leading technologies in this field. It is challenging to use 3D printing for a broader range of applications, especially in robotics, due to a lack of material options. Different materials are needed in the different parts found in sensors, actuators, and frames in robotics. Three-dimensional printers for metal do not print with plastics and vice versa. In plastics, some printers could only print PLA and ABS, but not all kinds of plastics.

Slow for Mass Production-3D printers consume plenty of time building single models or components compared with traditional manufacturing. The length of time will also be determined by the design's complexity, build size, and other parameters. In addition, other 3D printing processes are required to undergo post-processing steps, which further adds to the time in developing components or parts.

Copyright Issues-3D printing (AM) is becoming popular and accessible. Because of this, there is a greater possibility to create fake and counterfeit products that can be accessed through a shared repository. STL or OBJ files are the blueprint of all 3D models widely available on the internet, and some are downloadable for free. Furthermore, as technology advances and more people access it, a patent violation may become a significant issue. 


\section{3D Printing Polymeric Materials for Robots with Embedded Systems}

The emergence of additive manufacturing has allowed for the design and manufacturing of robots with plenty of complexity and functionality [102]. An increasing number of researchers have utilized 3D printing to design and propose robotic part fabrication methods, and some have even tweaked the mechanisms of 3D printers to use their material blends for robot printing. Table 2 lists the different $3 \mathrm{D}$ printing materials used in different robotic applications. From the table, it can be seen that polyethylene glycol diacrylate (PEGDA), flexible photopolymer (black) variant of TangoBlack Plus (which is proprietary), polylactic acid (PLA), acrylonitrile butadiene styrene, silicone, and elastomer-based materials are the most used materials to 3D print robots for its application, either for hard or soft robotic parts. Figure 5 shows some of the 3D printed robots with embedded systems mentioned in Table 2.

Table 2. 3D printing polymerics materials for robots with embedded systems.

\begin{tabular}{|c|c|c|}
\hline $\begin{array}{l}\text { 3D Printing } \\
\text { Technique }\end{array}$ & Material & Applications \\
\hline \multirow{14}{*}{$\begin{array}{l}\text { Fused Deposition } \\
\text { Modelling }\end{array}$} & Polylactic acid-based conductive graphene & $\begin{array}{l}\text { Multilayer composite, omni-direction soft cylindrical } \\
\text { actuator [34] }\end{array}$ \\
\hline & Polylactic acid & $\begin{array}{l}\text { Robotic structures and part [103] and flexure pressure } \\
\text { sensor [104] }\end{array}$ \\
\hline & Polylactic acid-graphene & Piezo-resistive tactile sensor [105] \\
\hline & Conductive polylactic acid & Soft actuators [106] \\
\hline & Acrylonitrile butadiene styrene & $\begin{array}{l}\text { Robotic tentacles, mainframes, main robotic frame [6], robot } \\
\text { molds [107], and actuator scaffold [108] }\end{array}$ \\
\hline & Acrylonitrile butadiene styrene -M30 & Robotic parts, robot face, jigs [109] \\
\hline & NinjaFlex 85 A & Soft pneumatic actuator [110] \\
\hline & Polycarbonate & Robotic components and aerospace applications [111] \\
\hline & Polycarbonate-ISO & Biocompatible (USP Class VI) [111] \\
\hline & $\begin{array}{l}\text { Polycarbonate-acrylonitrile butadiene } \\
\text { styrene }\end{array}$ & Robot components and end-use components [111] \\
\hline & Thermoplastic polyurethane elastomer & End-of-arm robot tool [112] \\
\hline & Conductive thermoplastic polyurethane & Electromyography electrode-driven soft robots [113] \\
\hline & Carbon fiber-filled silicone rubber & Soft robots [105] \\
\hline & Carbohydrate/sugar & Support material [48] \\
\hline \multirow{2}{*}{$\begin{array}{l}\text { Selective Laser } \\
\text { Sintering }\end{array}$} & Thermoplastic polyurethane (TPU92A-1) & Soft robotic hand [114] \\
\hline & Nylon or polyamide & $\begin{array}{l}\text { Hierarchical lattice [115] and soft robot kinematics for } \\
\text { snakes [116] }\end{array}$ \\
\hline \multirow{7}{*}{ Stereolithography } & Polyethylene glycol diacrylate (PEGDA) & $\begin{array}{l}\text { Miniaturized walking biological robots }[6,7,117] \text {, hydrogel } \\
\text { scaffolds [118], and biobot cantilever [117] }\end{array}$ \\
\hline & Elastomeric precursor, Spot-E resin & Octopus tentacles and actuators [119] \\
\hline & $\begin{array}{l}\text { Poly(ethylene glycol) diacrylate (PEGDA) } \\
\text { and acrylic-PEG-collagen (PC) mixtures }\end{array}$ & Biological machines and cantilever [117] \\
\hline & Silicone-based photo-cross-linkable resin & Fluidic elastomer actuators [115] \\
\hline & Semi-flexible polyethylene & Microelectromechanical systems [111] \\
\hline & Flexible resin (rs-f2-flgr-02) & Flexible articulated robotic hand [120] \\
\hline & Rigid resin (rs-f2-gpcl-04) & Joint holder for robotic hands [120] \\
\hline
\end{tabular}


Table 2. Cont.

\begin{tabular}{|c|c|c|}
\hline $\begin{array}{l}\text { 3D Printing } \\
\text { Technique }\end{array}$ & Material & Applications \\
\hline \multirow{8}{*}{$\begin{array}{l}\text { Polyjet- } \\
\text { Multimaterial } \\
\text { Printing }\end{array}$} & Polyethylene glycol & Soft caterpillar robots [121] \\
\hline & $\begin{array}{l}\text { Flexible, translucent photopolymer } \\
\text { (TangoPlus FLX930) }\end{array}$ & $\begin{array}{l}\text { Sensors, actuators, dielectric material/insulator [122], and } \\
\text { shape memory polymer [31] }\end{array}$ \\
\hline & $\begin{array}{l}\text { Flexible, black photopolymer } \\
\text { (TangoBlackPlus FLX980) }\end{array}$ & $\begin{array}{l}\text { Sensors, actuators [122], hydraulic robots [123], glove forms } \\
\text { [124], quadruped robots, leg actuator [125], and fluidic } \\
\text { elastomer actuator [126] }\end{array}$ \\
\hline & $\begin{array}{l}\text { Rigid, clear photopolymer } \\
\text { (VeroClear RGD810) }\end{array}$ & $\begin{array}{l}\text { Support material for robots, quadruped robots [122], leg } \\
\text { actuator [125], and fluidic elastomer actuator [126] }\end{array}$ \\
\hline & $\begin{array}{l}\text { Flexible, low-yield polymer } \\
\text { (SUP705) }\end{array}$ & Support material for robots [122] \\
\hline & $\begin{array}{l}\text { Transparent, rubber-like material } \\
\text { Objet TangoPlus }\end{array}$ & Functional tentacles [127] and pneumatic actuator [128] \\
\hline & Rubber-like material (FLX9070-DM) & Fluidic elastomer actuators [126] \\
\hline & Photopolymer (Veroblack) & Shape memory polymer [31] \\
\hline \multirow{2}{*}{ Direct Ink Writing } & $\begin{array}{l}\text { Dragon Skin } 10 \text { (DS10), two-part platinum } \\
\text { cure silicone ( } 1 \mathrm{wt} \% \text { Thi-vex and } 10 \mathrm{wt} \% \\
\text { silicone thinner), all smooth-on, and PA }\end{array}$ & Hexapus robot for radiation environments [27] \\
\hline & $\begin{array}{l}\text { Silicone, hydrogel, and polyacrylamide } \\
\text { elastomers }\end{array}$ & Sensing skin for robots [129] \\
\hline \multirow{2}{*}{$\begin{array}{l}\text { UV-Assisted 3D } \\
\text { Printing }\end{array}$} & $\begin{array}{l}\text { Flexible photopolymer adhesive } \\
\text { urethane-based secure SE- } 8143\end{array}$ & $\begin{array}{l}\text { Bio-metal, SMA-embedded } \\
\text { soft robot [33] }\end{array}$ \\
\hline & $\begin{array}{l}\text { Flexible photopolymer adhesive } \\
\text { epoxy-based secure SE- } 8272\end{array}$ & $\begin{array}{l}\text { Bio-metal, SMA-embedded } \\
\text { soft robot [33] }\end{array}$ \\
\hline $\begin{array}{l}\text { Magnetic } \\
\text { Field-Assisted } \\
\text { Projection } \\
\text { Stereolithography }\end{array}$ & Non-aqueous photocurable resin $\mathrm{E}$ & Soft robot [130] \\
\hline \multirow{4}{*}{$\begin{array}{l}\text { Shape Deposition } \\
\text { Modelling }\end{array}$} & Viscoelastic polyurethane & Cockroach limbs [131] and small robot limbs [132] \\
\hline & Two-part industrial polyurethanes & Robust grasper [133] \\
\hline & $\begin{array}{l}\text { Viscoelastic polyurethane, polyester fibers, } \\
\text { and low melting temperature wax }\end{array}$ & Performance and locomotion of robots [134] \\
\hline & Polyurethane elastomer & Soft grasper [135] \\
\hline
\end{tabular}

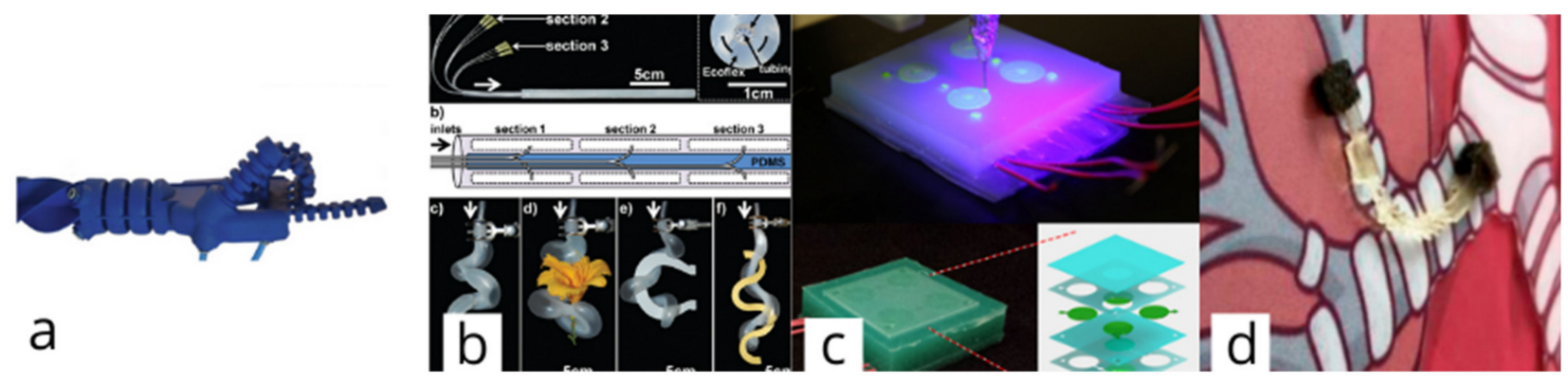

Figure 5. (a) Robotic hand made of elastic silicone [114]. Reprinted with permission from ref. [114]. Copyright 2021 Elsevier. (b) Polyjet-printed robotic tentacles made of polyethylene glycol [121]. Reprinted with permission from ref. [121]. Copyright 2021 John Wiley \& Sons. (c) DIW-printed robotic skin embedded with sensors [129]. Reprinted with permission from ref. [129]. Copyright 2021 Elsevier. (d) MAG-printed soft robot, also made of Spot E [130]. Reprinted with permission from ref. [130]. Copyright 2021 Elsevier. 


\subsection{Fused Deposition Modelling}

\subsubsection{Polylactic Acid}

Soft actuators are used in different robotic applications, from biomedical to inspection, which require control, complexity, precision, and fast movement. For example, an omnidirectional actuator was designed and fabricated by Gul et al. in 2017 [34]. The actuator was fabricated using different fabrication methods, such as 3D printing. The graphene conductive rod was fabricated using fused deposition modelling (FDM) along with the cylindrical shape memory polymer (SMP) with polylactic acid (PLA) as the base material. The 3D printed graphene rod was then inserted into the cylinder with a shape memory alloy (BMF150), which was used to bend the catheters in a single direction through the thermal signals.

PLA was also used to produce robotic structures and parts [103] and flexure pressure sensors [104]. In some applications, PLA with graphene (PLA-G) was also used in the composite form to fabricate piezo-resistive tactile sensors. The repeatability of the sensing function was found to be promising across a wide range of strains induced by bending [136].

The stiffness tuning characteristics of conductive PLA (CPLA) were studied by $\mathrm{Al}$ Rubaiai et al. [106] for soft robotic applications of CPLA. The mechanical, thermoplastic, and electrical properties of CPLA were characterized and were found to reduce Young's Modulus by $98.6 \%$ from $1 \mathrm{GPa}$ at room temperature to $13 \mathrm{MPa}$ at $60^{\circ} \mathrm{C}$. A soft actuator was fabricated, and its ability to grasp based on the shape and size of the object being grasped demonstrated effectivity with the desired bending configuration without voltage pressure.

\subsubsection{Acrylonitrile Butadiene Styrene}

Acrylonitrile butadiene styrene was used for robotic parts such as tentacles, mainframes, frames [6,127], molds [107], and even as scaffolding for actuators [108]. For example, in a collaboration between Stratasys and Stan Winston School [109], they 3D printed a robot that weighed 400 pounds and was 9.5 feet tall. The project used a variety of 3D printers to complete the project. The parts were printed using acrylonitrile butadiene styrene (ABS-M30), a 3D printing material with robust mechanical properties ideal for model parts for prototypes, fixtures, and tools. Shi et al. [104] presented a 3D printed flexure pressure sensor for robot impact safety testing, wherein polylactic acid (PLA) was used as the printing material. The sensor was incorporated with a biosimulant from the National Institute of Standards and Technology (NIST) to measure the precision of the impact of the robot interacting with humans. Their work concluded that the structural pressure sensor was easy to create, low-cost, and disposable. They also obtained a loading force of $0.028 \mathrm{~N}$ from a finite element model.

\subsubsection{NinjaFlex $85 \mathrm{~A}$}

Ninjaflex 85A (a proprietary material from Ninjatek, Pennsylvania, USA) is a thermoplastic elastomer filament with a Shore hardness of 85 A. Yap et al. [110] proposed an FDM-based 3D printing technique to produce a bellows-type actuators from the bottom part, which does not include any core for defining and molding the inner geometry. The proposed technique enables the customization of actuator geometries by adjusting and modifying the printing parameters in the slicing software. The actuators were printed using an FDM 3D printer with Ninjaflex 85A as the material. The print settings were set at $0.1 \mathrm{~mm}$ for the layer thickness, while the nozzle diameter was $0.4 \mathrm{~mm}$. Deformation was observed, which was due to the fast movement of the nozzle during the printing process. Hence, when using the material, a significant airflow presence in the environment is not recommended. During the printing process, the actuators were printed sideways.

Consequently, the wall of the bellows is printed in a longitudinal direction, attaining a higher strength when compared with the walls that were printed transversely. The printing direction also contributed to the rounded edges, which were ideal for reducing the stress during actuation. Unlike other 3D printed actuators requiring permanent sealing, the developed actuators in the study did not need post-processing. The actuators were able 
to provide the flexion and extension of the fingers. The method used for the production was also found to enable the development of 3D printable exoskeletons for wearable applications and soft robotics. However, the actuators were unsuitable in low-pressure environments and applications needing delicate force outputs [110].

Prostheses, orthoses, and robotics utilize sensors wherein they are installed in soft structures. Soft structures, however, were found to hinder the installation of sensors. Improvements in 3D printing materials and development in AM technologies have paved the way for possibilities of integrating sensors on soft structures found in robots. Wolterink et al. [113] characterized the performance of 3D printed electrodes to gain insight on the influence of size on the signals of the EMG. Conductive PI-ETPU was used for the grey part in Figure 6, while the orange parts are made of non-conductive Ninjaflex so as to keep electrodes distant. Both are flexible materials are ideal for soft robotics [113,137].
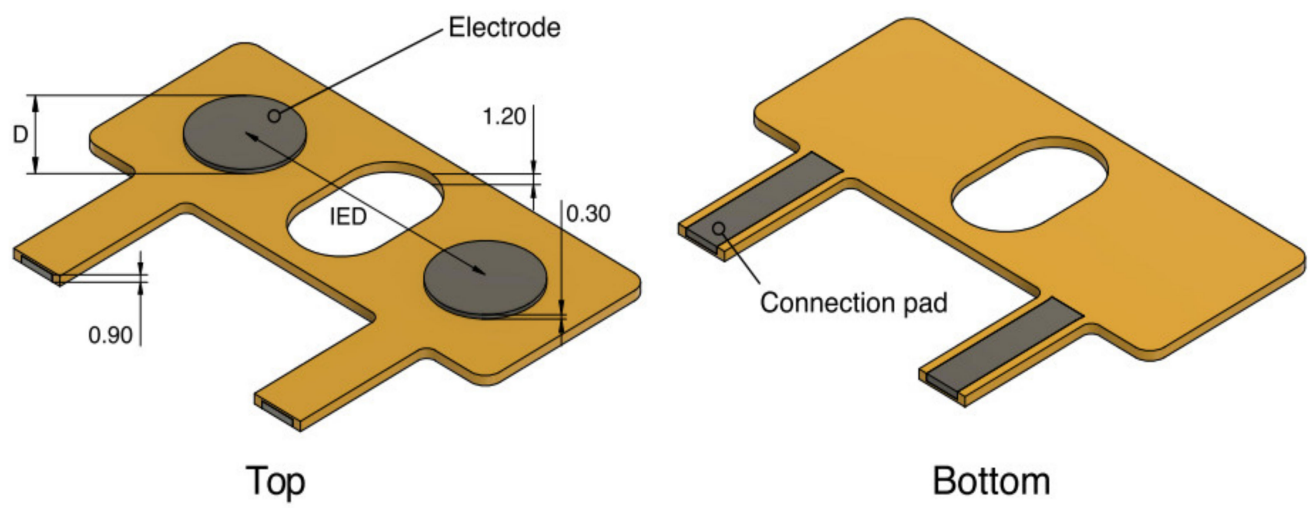

Figure 6. CAD drawing of the electrodes; the gray parts are made of conductive PI-ETPU while the non-conductive segment is made of non-conductive Ninjaflex [137].

The parts were printed using the Flashforge Creator Pro FDM 3D Printer equipped with two extruders capable of printing flexible materials. The structures were printed with a layer height of $150 \mu \mathrm{m}$, while the first layer was $300 \mu \mathrm{m}$. The sensors were then placed on the wrist and tested on volunteer patients. The structure successfully produced the same range, noise, and lower energy with regular $\mathrm{AgCl}$ electrodes. The structure also required minor post-processing and was easily scalable and customizable. These features make the structure more accessible for various applications such as robotics. Something that needs more study to improve this technology would be the integration of electrodes into prosthesis and robotics by directly using 3D printing without the other steps required. This idea only shows that 3D printing electrodes and embedding them on other materials are ideal for prolonged and multiple uses in prostheses and robotics compared with the $\mathrm{AgCl}$, which can only be used once $[113,137]$.

Other materials mentioned in Table 2 were found to have been integral in producing robotic components for different applications. Polycarbonate was found to be ideal for aerospace applications along with robotic component manufacturing. Its other variants, such as polycarbonate-ISO, were deemed biocompatible. PC-ABS was also found to be ideal for robot components and end-use components [111]. Materials such as thermoplastic polyurethane elastomers, conductive polyurethane, carbon fiber-filled silicone rubber, and even sugar were also found to be beneficial for FDM printing of robotic parts and their components.

\subsection{Selective Laser Sintering}

Thermoplastic Polyurethane (TPU92-1)

An approach to the integration of actuators, sensors, and structural components into a single piece was presented by Scharff et al. [114]. A soft robotic hand was designed and fabricated to adhere to the desired functions so as to demonstrate human-like behaviors. The soft robotic hand was printed using selective laser sintering (SLS) with TPU92-1 as 
the material. It took $12.5 \mathrm{~h}$ to produce the part. The work showed that the design of the behavior sets was not based only on the existing robotic components. Hence, bending actuators, rotational actuators, bidirectional actuators, and sensing air chambers could be embedded in the robotic hand design through SLS [114].

\subsection{Stereolithography \\ Polyethylene Glycol Diacrylate}

Chan et al. [117] created a biological machine (i.e., bio-bot) that was designed with an actuation module for the sake of locomotion. An array of bio-bots was printed using a multi-material SLA printer. Each robot was decked with a biological bimorph cantilever and a base structure. The cantilevers were printed with polyethylene glycol diacrylate (PEGDA). A pattern was first traced on a layer of PEGDA, a hydrogel precursor solution using an ultraviolet beam. It was then re-coated with another layer of PEGDA. This process was repeated until the structural design was completed. The material for the cantilever was chosen based on its capability to mimic the elasticity of heart muscles of rats, while the base was meant to be rigid enough to retain its shape. The bio-bot demonstrated an efficient locomotion mechanism that maximized the use of contractile forces to overcome frictional forces while preventing the backward movement of the legs during the relaxation process [117].

\subsection{Polyjet Multimaterial Printing}

Flexible Photopolymers (Translucent, Black, Clear, and Low-Yield)

Soft robots are often integrated with sensors to improve their exteroceptive and interoceptive capabilities. Shih et al. [138] designed sensors that can be co-produced or fabricated with robots using commercially available 3D printers. Resistive soft sensors were designed and fabricated using a Connex Object 350 multi-material 3D printer with flexible photopolymers that are translucent, black, clear, and low-yield as the materials. The multimaterial method of printing with the materials mentioned here allowed for the design of robots with different mechanical and electrical properties. However, as the materials were not designed as conductors for robotic design, the resistance had a larger magnitude. The photopolymers also experienced limited strains, unlike the silicone elastomers, limiting their application in robotics [122].

\subsection{Direct Ink Writing}

6.5.1. Dragon Skin 10 (ds10), Two-Part Platinum Cure Silicone (1 wt \% Thi-Vex and $10 \mathrm{wt} \%$ Silicone Thinner), and All Smooth-On PA

Yirmibesoglu et al. [139] presented a customized 3D printer with an extrusion mechanism to produce soft functional robots. The work focused on direct ink writing (DIW) techniques and utilized polydimethylsiloxane (PDMS). PDMS was also used in molding, which was compared with the 3D printed parts. Dragon Skin 10 (Smooth On, USA), a platinum curable silicone, was used as the primary material in PDMS formulation. It comes in two parts, a base and a crosslinking agent, that, when blended, cure into a solid rubber material. A thickening agent Thi-Vex (Smooth On, Macungie, Pennsylvania, USA) was used to improve the viscosity of the formulation, which would eventually lead to improved print fidelity. Over-extrusion and under-extrusion of the silicone material were faced during the trial-and-error phase. However, parameters were altered one by one to determine the effects on the printed lines.

For the final printing parameters, the following were used: (a) layer thickness / height $=1.3 \mathrm{~mm}$, (b) infill $=100 \%$, (c) printing speed $=7 \mathrm{~mm} / \mathrm{s},(\mathrm{d})$ nozzle diameter $=1.3 \mathrm{~mm}$, and (e) bed plate temperature $=50^{\circ} \mathrm{C}$.

The work concluded that upon analysis of the failure pressure results, 3D printed robots were more rigid, more dependable, and had a less dimensional error than their molded counterparts, while reducing production time by as much as $50 \%$. The printed robots were also on par with the performance of the molded ones. The work considered 
further investigations on a phenomenon termed the "sewing thread effect" - a term created to define the surface of the printed actuators that look threaded; to elucidate why the printed robots could withstand more pressure without expansion while having a similar thickness to their molded counterparts [139].

\subsubsection{Silicone, Hydrogel, Polyacrylamide Elastomers}

Robots are now gently interacting with organisms, conforming to their environment, and performing complex motions through actuations. These types of robots are usually composed of elastomer-based materials like silicone with embedded pneumatic channels for actuation. Robinson et al. presented a highly extensible skin combinable with pneumatic actuators produced via direct ink writing [129]. The sensing skin allows soft machines to perceive the stimuli and shape, leading to the robots' tactile and kinesthetic sensing abilities. Two viscoelastic fluids were developed, namely a hydrogel elastomer precursor and a silicone elastomer precursor. The two fluids were crosslinked using in-situ photopolymerization into conductive hydrogels and were insulated silicon with a large ultimate strain.

They were then printed onto soft pneumatically-powered haptic displays (PHD). No exposure to UV light was necessary after the printing process. The rheological properties of the elastomer precursors enabled the formulation of viscoelastic patterns directly onto the actuators of the haptic displays. The skin allowed the PHD to recognize a compression of $\sim 2 \mathrm{~N}$ and an internal pressure as low as $\sim 10 \mathrm{~N}$, which was affirmation of a soft, feedbackcontrolled interface for the PHD. The skin adhered excellently and did not delaminate when $\sim 65 \mathrm{kPa}$ of pressure was applied to the actuating chamber. However, the inextensible sealing layer only delaminated due to the PneuNets being operated at high-pressure levels.

The work concluded that the skin developed could replicate the natural ability of biological skin and localize the touch sensations. This low-cost design using tactile and kinesthetic sensors will improve robots tasked to perform repetitive tasks in working environments performing search and rescue and domestic care close to humans. The above-mentioned work could also improve the living conditions of amputees by enabling intuitive use and adjustment of prosthetic devices [129].

\subsection{UV-Assisted 3D Printing}

Epoxy-Based Secure SE-8272 and Urethane-Based Secure SE-8143

Progress in shape memory alloy (SMA) muscle-powered soft robots is limited. As a result, Gul et al. presented a unique tri-legged soft bot that could mimic a spider's multi-step. The soft bot could be controlled by contracting the bio metal fiber (BMF) using a type of SMA muscle. A customized UV-3D printing system was used to produce the polymer parts with two photopolymer adhesives, namely Epoxy-Based Secure SE-8272 and Urethane-Based Secure SE-8143, as the materials. The design was reported to have a stable motion at a speed of $2.7 \mathrm{~mm} \mathrm{~s}^{-1}$ [33].

\subsection{Magnetic Field-Assisted Projection Stereolithography \\ Non-Aqueous Photocurable Resin E (Spot E)}

Joyee et al. proposed a robot made of various materials and a compliant body structure with a magnetic particle-polymer that was directly 3D printed. The robot was composed of two parts: a flexible body section and a functional part, controllable externally by magnetic fields [102,140]. Based on the proposed strategy for design, four designs were finalized. A comparison was performed among the four designs to achieve the highest bending angle and locomotion capabilities through finite element analysis (FEA) using commercial software. To produce the designs, a multi-material 3D printing method was employed. Magnetic field assisted projection stereolithography (M-PSL) is a multi-material 3D printing process that can produce composite structures layer by layer. The other details regarding their robot manufacturing technique and parameters were similar to their previous studies $[140,141]$. Spot E, a non-aqueous photopolymer, was used as the base 
polymer matrix. This particular type of resin is translucent in color and has good elastic properties, giving the composite more freedom to bend or deform easily [142]. As for the functional parts of the robot, EMG 1200 or dry magnetic nanoparticles with a nominal diameter of $10 \mathrm{~nm}$ were utilized as the magnetic filler. The former robot prototype had drawbacks in terms of its versatility and adaptation in wet and slippery surfaces. Design modifications must be addressed to increase the grip on surfaces. The leg materials were also required to have hydrophobic properties to operate successfully on dry and wet surfaces. Lastly, the resin and polymer composites used were not biocompatible [130].

In another research work, Joyee et al. also proposed a 3D-printed monolithic and tetherless soft robot inspired by inchworms. It utilized magnetic actuation for its crawling and locomotion. Spot E of Spot A Materials from Barcelona, Spain, was used as the resin. It is a flexible resin that exhibits an exceptional level of toughness. It can also elongate up to $65 \%$ after being cured-this was based on ISO 527 1-A Standard. Synthetic black iron oxide nanoparticles were mixed with the Spot E resin to prepare the magnetic field composites. The polymer material was able to act as muscle tissue, and locomotion was made possible through magnetic field actuation, while the use of a multi-material 3D printing process allowed for fast production and an assembly-free design. The robotic design and materials were concluded to be applicable in rescue and other applications not accessible by giant rigid robots [102].

\subsection{Shape Deposition Modelling \\ Two-Part Industrial Polyurethane}

The compliance of robotic grippers maximizes the range of positions for the successful grasp of objects. Dollar et al. presented a gripper fabricated using shape deposition modeling to reduce complexity while increasing the robustness. Two-part (two-component) industrial polyurethane was used as the material. Innovative Polymers, St. Johns, MI, USA, formulated and trademarked the material for casting equipment. The transparent color of the polymer (polyurethanes) allowed the embedded components to be seen, and another advantage was that it had a functionality similar to metal prototypes, but had a far superior robustness. The performance of the grasper and its properties were found to be desirable [133].

The appropriateness of a material in its application can be a massive advantage for producing 3D-printed robots and their parts. Rigid materials such as PLA, PC, and ABS are ideal for cylindrical actuators, jigs, mainframes, structures, and parts for FDM processes. Meanwhile, polyurethane-based materials are appropriate in FDM printing robot tools and electromyography electrode-driven robots. Silicone rubber is also used to produce soft robots, while sugar can be considered a sacrificial material for supports.

In SLS processes, TPUA92A-1 is appropriate for printing soft robotic hands due to its elasticity. Meanwhile, nylon or polyamide can be used to print trusses and soft kinematics for robotic snakes. For SLA processes, PEGDA is suitable for printing biological robots, hydrogel scaffolds, and other biological machines. At the same time, flexible materials such as silicone-based resin and flexible resin can be used in flexible robotic hands actuators and soft robots. There are various materials in polyjet multi-material printing, such as polyethylene glycol, that can be used to print sensors, actuators, insulators, and shape memory polymers. The photopolymers mentioned here work well for various robotic part printing, such as for sensors, actuators, support materials, leg actuators, and tentacles. For DIW, only two materials are listed. They are suitable for printing robots that can be employed in radiation environments and as sensing skin for robots. In UV-assisted 3D printing, flexible materials are suitable in producing SMA-embedded robots. Lastly, in SDM, polyurethane-based materials are used to produce graspers and limbs.

\section{Discussions and Future Outlook}

Three-dimensional printing is one of the fastest-growing technologies and is continuously gaining popularity in innovations and new opportunities in the electronics and 
robotics industry. For the robotics and automation industry, most manufacturers provide efficient designs that have potential in the AM industry, wherein in 2019, the Robotics Industries Association had orders for robots up by $5 \%$ and worth $\$ 1.3$ billion [143]. In general, the industry for 3D printing was worth $\$ 3$ billion in 2013, which had grown to $\$ 7$ billion in 2017. By 2025, the AM industry is forecast to have more than $\$ 20$ billion market value [143].

There are some notable outlooks for 3D printing and its materials, as it offers unique advantages that are beneficial to the fabrication of robotics with embedded systems. It can integrate actuators, sensors, power systems, and controls through the introduction of more disruptive methods of additive manufacturing. The presence of multi-material 3D printers will likely benefit from the vast selection of continuously developing materials. This idea will open more opportunities to produce soft robots using reversible materials, i.e., materials that regain their structure/shape/form during shape-shifting operations, which is vital in this field.

Some issues of 3D printing materials that must be studied further are biocompatibility, non-uniform shrinkage, anisotropy, and adhesion during multi-material printing. These issues might result in premature failures of the embedded robots and generate large amounts of waste due to failed test prints and unwanted prototypes during the development process. Progress in materials science and additive manufacturing will allow for more materials in additive manufacturing processes and robotics. This includes the gradients of softness and hardness to allow the robots more locomotion without overstretching the materials and losing their original structure. The biggest hindrance in integrating 3D printing with robotics is still the availability of 3D printing materials and their characteristics. Giving importance and much consideration to incorporating post-processing operations from the design phase may also increase the use cases of 3D printing in this field [144].

\section{1. $4 \mathrm{D}$ Printing and Smart Materials}

Four-dimensional printing can also address some issues in robotic printing. Fourdimensional printing is when a 3D printed object transforms itself into another structure due to the influence of external energy inputs such as light, temperature, or other environmental stimuli. This is possible through the use of innovative materials that have a shape-changing capability. It can produce artificial muscles for robots and prosthetics that are almost similar to biological functions as it can react to certain stimuli upon contact. It can also be used to produce biocompatible materials or parts, which is often favorable for robotic applications, with the transformation being induced by certain stimuli such as temperature, $\mathrm{pH}$ levels, humidity, and light [7]. However, this is subject to applications that require reversible shape changes, such as robot parts. It can also produce complex parts such as a cardiac stent to keep vessels open. It can be in line with the previously mentioned work, wherein a 3D printed robot was employed to deliver drugs to the stomach [145]. Lastly, the temperature transition points of the materials could be further fine-tuned depending on the application and environment where they will be utilized $[136,146]$.

A proposed manufacturing strategy might be a combination of various manufacturing methods. However, due to the current limits of additive manufacturing, the process itself must be improved first. Through its development, direct and multi-material fabrication of embedded robotics with sophisticated design and functions will be done in the future. The development of smart materials for 3D printing embedded robotics will pave an avenue for developing more advanced robots that can be used in different applications, ranging from biomedical, construction, inspection, and sensing. The utilization of smart materials that are merged with nanomaterials, nanocomposites, and hydrogels will provide more demand and development for customized robots. Some materials that need further discovery and development must possess characteristics and the ability to retain their shape despite being stretched regularly, it also must be functional and responsive to a lot of external stimuli such as light, temperature, $\mathrm{pH}$ levels, and other parameters. This can be done on elastomers and other polymers. However, this can only be achieved via $4 \mathrm{D}$ printing, which 
needs more research and development. Despite the limits of both technologies, it cannot be denied that the advancement of novel materials and sophisticated techniques will resolve all issues faced by researchers [7,147]. Four-dimensional printing using smart materials can also be enabled by appropriate post-processing operations [144].

\subsection{Continuous Liquid Interface Production}

Printing robotics can be effectively determined by the optimization of the manufacturability and the functionality of its material. Hence, the versatility of AM methods and techniques push forward the possibility of producing more complex geometries, materials, and functions. A printing method called continuous liquid interface production (CLIP) was developed and patented in 2014. CLIP uses a non-stop sequence of UV images through a transparent window below a liquid resin tank that can be permeated by oxygen. A dead zone created above the mentioned window has a maintained liquid level below the moving or advancing part. The part that is being cured is drawn out [59]. This creates suction that renews the reactive liquid resin present in the process, as seen in Figure 7 [148]. CLIP is currently being used to produce parts from oil-based materials deemed non-ideal for biomedical engineering applications. However, it can be used to print hydrogels, load-bearing materials, and flexible electronics for potential utilization in robotics [149].

\section{Platform continuously moving up}

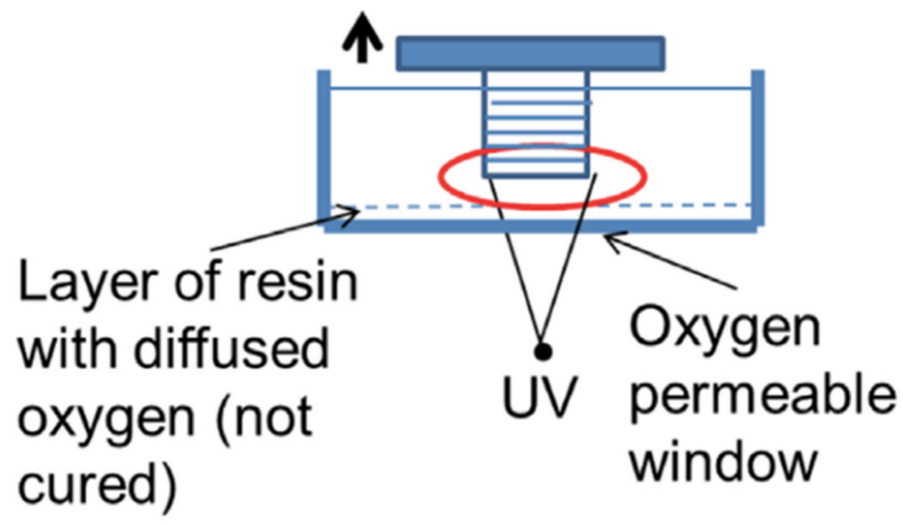

Figure 7. Continuos liquid interface production [148]. Reprinted with permission from ref. [148]. Copyright 2021 Elsevier.

\subsection{Biocompatibility of 3D Printing Materials}

With regards to possible alternative materials, Chen et al. [15] formulated a blend of thermoplastic urethane (TPU) and polylactic acid (PLA) with graphene oxide (GO). TPU is an elastic polymer that has flexible polyesters and polyethers as soft segments. For its hard segments, it can contain benzyl and diisocyanates. As for its characteristics, TPU has good biocompatibility and exceptional mechanical properties such as abrasion resistance, tensile, elongation, and compression strength [15]. The drawbacks of TPU are low mechanical toughness and low shape firmness [150-153].

Meanwhile, polylactic acid is strong, but it can also be very brittle in terms of its low flexibility and resistance to impact [154-157]. The study by Chen et al. [15] found that blending the two thermoplastics improved the mechanical strength, shape memory, and resistance to impact. Adjustments in ratios will lead to the satisfaction of various requirements in applications without any difficulty.

Lastly, graphene is a single layer of $\mathrm{sp}^{2}$ carbon atoms that are considered hybridized. It offers excellent electrical, thermal, and mechanical properties. Graphene is also known to contain antimicrobial effects [9-15]. The work concluded that the 3D printed nanocomposite made of a mixture of PLA, TPU, and GO showed excellent properties, thermally and mechanically, as well as cell viability, which allowed the nanocomposite to be used in various fields and as a good potential in tissue engineering fields $[15,18,158,159]$. 


\subsection{Sugar as Printing Supports}

Hamidi and Tadesse [48] studied the material properties of molten carbohydrates, which were employed as a support material for 3D printing silicone, as shown in Figure 8. The carbohydrates were composed of sugar, alcohol, and table sugar; they could be any mixture of the two ingredients. For their 3D printing process, the molten carbohydrate was extruded and solidified at room temperature to become stiff enough to support the silicone materials. It was found to stick well to the silicone, and it could also be removed easily by submerging in warm water. An advantage of using carbohydrates as a support material is that it can be removed between 3D printed silicone layers; the hollow channels will then be used for pneumatic actuation. Figure 8 shows the printing process and silicone before and after dissolving the sugar support. Their work highlighted the material processing and parameters for 3D printing silicone by eliminating assembly and post-processing. The elongation of 3D printed silicone in uniaxial tensile tests, and the mechanical characterization and fabrication of soft pneumatic and hydraulic actuators using silicone and carbohydrate glass to demonstrate the potential applications of their 3D printing method in the creation of functional robots and robotic structures were also discussed. They concluded that carbohydrates could be used as sacrificial support materials for 3D printing processes that involve silicone materials for its application in soft robotics [48].

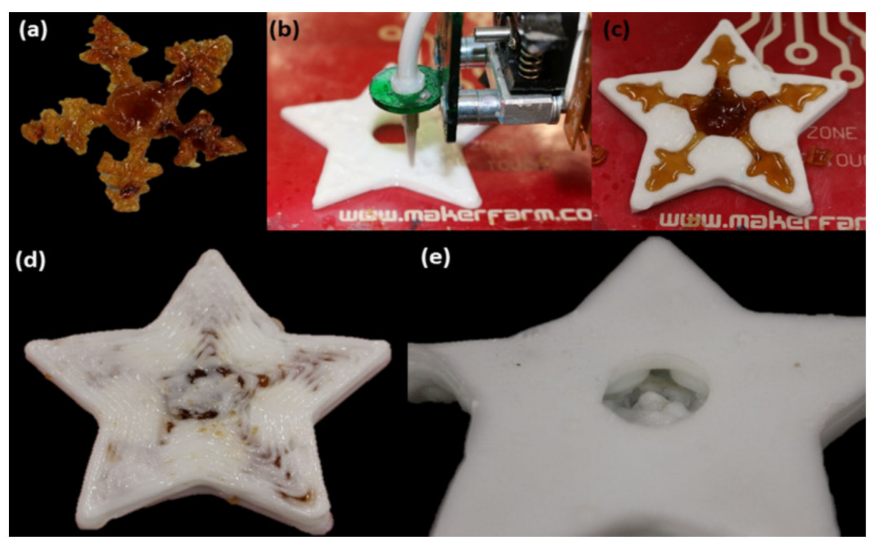

Figure 8. Procedure for printing a silicone structure with hollow channels with carbohydrate glass as support material: (a) 3D printed carbohydrate glass, (b) 3D printed silicone structure, (c) 3D printed carbohydrate glass embedded in the silicone structure, (d) printed layer of silicone atop the carbohydrate glass layer, and (e) hollow channels after carbohydrate glass dissolving [48]. Reprinted with permission from ref. [48]. Copyright 2021 Elsevier.

\subsection{Volumetric Additive Manufacturing}

Another interesting technology that can be incorporated with 3D printing robots with embedded systems is volumetric additive manufacturing. Like other 3D printing techniques such as SLA, this printing method is also light-based. This method depends on a viscous prepolymer that cures when exposed to light. A series of light patterns called "movies" are projected onto a rotating cylinder containing the prepolymer. The desired shape will then be formed and solidified after some time.

Some of the complexities in volumetric additive manufacturing include formulating materials and the computation of images for projection to get the exact complexity of the shapes and intensities correctly. The technique also generates almost no waste as it is support-free printing, while the uncured materials used in prior printing are deemed to be $100 \%$ reusable $[160,161]$. 


\subsection{D Printing Issues \\ 7.6.1. Non-Uniform Shrinkage}

FDM usually uses thermoplastic materials that are prone to high shrinkage due to thermal retractions, leading to inaccuracies in dimension and shape warping. Materials used in FDM, such as ABS, have been found to shrink during the printing process when in contact with air. Hence, a heated bed and an enclosure are always recommended whenever it is used [162]. Meanwhile, for SLA, discrepancies in dimension are observed in tall printed parts. In some SLA printers, there is a peeling process. The pulling force during the process causes the partially cured layers to bend. In this case, prepolymers that possess higher flexural properties are more prone to warping. SLS can produce parts and complex geometries accurately. Warping and shrinking are prevented due to their use of build chambers that heat the powder below the sintering temperature. To further prevent the warping of parts, the printed parts are sometimes left in the chamber to cool gradually. Compared with the other 3D printing processes mentioned, material jetting is considered the most capable of producing accurate parts because no heat is involved in its process. This is why warping and shrinkage rarely occur. However, the utmost care is required when handling the printed parts as they can warp once exposed to ambient heat, humidity changes, and sunlight [163].

\subsubsection{Anisotropy}

In terms of strength, 3D printing parts are noted to possess immanent anisotropic properties. This is often observed, mostly in FDM parts, which are much more robust in the XY direction than the $\mathrm{Z}$ direction [164]. Despite being melted on top of each layer, FDM prints only create a mechanical adhesion, not a chemical one. Hence, layers are only partially adhered to one another and are observable under the microscope, where voids in layers can be found. This is another reason FDM prints are not often used in water applications.

On the other hand, SLA prints do not possess indifferent chemical bonds per layer. The monomers form a covalent bond that forms a high lateral strength despite an incomplete polymerization reaction during the process. The printing process only turns the monomers into a semi-reacted situation known as the "green state." The reaction will incorporate other groups into the previous layers, as succeeding layers are partially cured due to covalent bonding. This is a typical crosslinking found in SLA printing, and due to this, there are no voids or cracks found in SLA. SLA prints are also known to be watertight and dense, unlike FDM prints [165]. SLS, which uses Polyamide 12 (PA12), is also anisotropic between vertical and horizontal directions. It was also observed that the worst set of mechanical properties were obtained when printed in the $\mathrm{Z}$ direction. However, it was also found to be isotropic. These contrasting results were due to the low level of anisotropy in laser sintering. Lastly, anisotropy in parts made through DLP was removable when post-cured in areas where UV light does not pass through during the printing process [166].

\subsubsection{Multi-Material Adhesion}

An usual method of multi-material adhesion is by bonding through an adhesive application. It is an effective process of joining dissimilar polymers. However, this usually involves two separate 3D-printed components. Despite drawbacks in the limited usage of AM in manufacturing, its potential, which includes multi-material adhesions, has been continually researched and developed to move forward. A multi-material additive manufacturing (MM-AM) method is thought to make composites, alter properties, and make new materials completely. The method is expected to further develop in the near future with the aid of material development [41].

\section{Summary and Conclusions}

Three-dimensional printing paved the way for the advancement of embedded robot manufacturing through $3 \mathrm{D}$ printing materials that are now considered for specific applica- 
tions. This review gives a brief overview of 3D printing materials for robots with embedded systems. The cited research demonstrates the $3 \mathrm{D}$ printing materials discussed, and their advantages and disadvantages are presented along with their specific applications.

- In most robotic applications, soft materials such as PEGDA, silicone, and elastomerbased materials are mainly used due to their elastic properties. For hard materials, PLA and ABS are favored.

- As for the support, some studies cited the use of carbohydrates to create hollow channels in robotic parts.

- The compilation and synthesis of these studies might be used as a basis for robotics enthusiasts to select materials for their specific application. However, as some materials are newly developed, the 3D printing processes and mechanisms must be tweaked to utilize these materials for robots with embedded systems.

- The key areas that need further investigation are the blending/formulation of materials to improve mechanical properties, costs, and inclusion of specific materials for intended applications. The formulation of new 3D printing materials can shift the paradigm for both $3 \mathrm{D}$ printing and robotics, as both are promising technologies for diverse applications. Newly formulated materials, 3D printing technologies, and post-processing technologies must be developed to fully reach the potential of utilizing the 3D printing technology for robots with embedded systems applications.

- A future outlook regarding the combination of these technologies has also been incorporated into the discussions.

Author Contributions: Conceptualization, J.R.C.D. and J.-J.C.; methodology, J.-J.C., J.R.C.D. and R.N.M.D.; formal analysis, J.-J.C., R.N.M.D. and J.R.C.D.; writing-original draft preparation, R.N.M.D., R.B.B., R.P.H. and J.R.C.D.; writing-review and editing, J.-J.C., R.N.M.D. and J.R.C.D.; editing and proofreading, D.W.C.M.; R.N.M.D. and J.R.C.D.; funding acquisition, J.-J.C. and J.R.C.D. All authors have read and agreed to the published version of the manuscript.

Funding: This work was partly supported by a research grant from Qatar University under grant no. M-CTP-CENG-2020-4, and by the Research and Development Office of the Bataan Peninsula State University. The statements made herein are solely the responsibility of the authors.

Acknowledgments: R.B.B. and R.P.H. would like to thank the support of the Department of Science and Technology of the Philippine Council for Industry, Energy, and Emerging Technology Research and Development (DOST-PCIEERD), and J.R.C.D. and R.N.M.D. acknowledge the support of the Research and Development Office of the Bataan Peninsula State University (BPSU).

Conflicts of Interest: The authors have no relevant financial or non-financial interest to disclose.

\section{References}

1. Dizon, J.R.C.; Espera, A.H.; Chen, Q.; Advincula, R.C. Mechanical characterization of 3D-printed polymers. Addit. Manuf. 2018, 20, 44-67. [CrossRef]

2. Delda, R.N.M.; Tuazon, B.J.; Dizon, J.R.C. Assessment of interfacial adhesion of adhesively bonded 3d-printed thermoplastics. Mater. Sci. Forum 2020, 1005, 157-165. [CrossRef]

3. Dizon, J.R.C.; Valino, A.D.; Souza, L.R.; Espera, A.; Chen, Q.; Advincula, R.C. 3D Printed Injection Molds Using Various 3D Printing Technologies. Mater. Sci. Forum 2020, 1005, 150-156. [CrossRef]

4. Dizon, J.R.C.; Valino, A.D.; Souza, L.R.; Espera, A.; Chen, Q.; Advincula, R.C. Three-dimensional-printed molds and materials for injection molding and rapid tooling applications. MRS Commun. 2019, 9, 1267-1283. [CrossRef]

5. Salem, M.E.M.; Wang, Q.; Wen, R.; Xiang, M. Design and Characterization of Soft Pneumatic Actuator for Universal Robot Gripper. In Proceedings of the International Conference on Control and Robots (ICCR), Hong Kong, China, 15-17 September 2018; pp. 6-10. [CrossRef]

6. Gul, J.Z. 3D printing for soft robotics-A review. Sci. Technol. Adv. Mater. 2018, 19, 243-262. [CrossRef]

7. Falahati, M.; Ahmadvand, P.; Safaee, S.; Chang, Y.-C.; Lyu, Z.; Chen, R.; Li, L.; Lin, Y. Smart polymers and nanocomposites for 3D and $4 \mathrm{D}$ printing. Mater. Today 2020, 40, 215-245. [CrossRef]

8. Espera, A.H.; Dizon, J.R.C.; Chen, Q.; Advincula, R.C. 3D-printing and advanced manufacturing for electronics. Prog. Addit. Manuf. 2019, 4, 245-267. [CrossRef]

9. Advincula, R.C.; Dizon, J.R.C.; Chen, Q.; Niu, I.; Chung, J.; Kilpatrick, L.; Newman, R. Additive manufacturing for COVID-19: Devices, materials, prospects, and challenges. MRS Commun. 2020, 10, 413-427. [CrossRef] 
10. Tijing, L.D.; Dizon, J.R.C.; Ibrahim, I.; Nisay, A.R.N.; Shon, H.K.; Advincula, R.C. 3D printing for membrane separation, desalination and water treatment. Appl. Mater. Today 2020, 18, 100486. [CrossRef]

11. Valino, A.D.; Dizon, J.R.C.; Espera, A.H.; Chen, Q.; Messman, J.; Advincula, R.C. Advances in 3D printing of thermoplastic polymer composites and nanocomposites. Prog. Polym. Sci. 2019, 98, 101162. [CrossRef]

12. Tuazon, B.J.; Espino, M.T.; Ryan, J.; Dizon, C. Investigation on the Effects of Acetone Vapor-Polishing to Fracture Behavior of ABS Printed Materials at Different Operating Temperature. Mater. Sci. Forum 2020, 1005, 141-149. [CrossRef]

13. Espino, M.T.; Tuazon, B.J.; Robles, G.S.; Dizon, J.R.C. Application of Taguchi Methodology in Evaluating the Rockwell Hardness of SLA 3D Printed Polymers. Mater. Sci. Forum 2020, 1005, 166-173. [CrossRef]

14. De Leon, A.C.; Chen, Q.; Palaganas, N.B.; Palaganas, J.; Manapat, J.; Advincula, R.C. High performance polymer nanocomposites for additive manufacturing applications. React. Funct. Polym. 2016, 103, 141-155. [CrossRef]

15. Chen, Q.; Mangadlao, J.D.; Wallat, J.; de Leon, A.; Pokorski, J.K.; Advincula, R.C. 3D Printing Biocompatible Polyurethane/Poly(lactic acid)/Graphene Oxide Nanocomposites: Anisotropic Properties. ACS Appl. Mater. Interfaces 2017, 9, 4015-4023. [CrossRef]

16. Wei, P.; Leng, H.; Chen, Q.; Advincula, R.C.; Pentzer, E.B. Reprocessable 3D-Printed Conductive Elastomeric Composite Foams for Strain and Gas Sensing. ACS Appl. Polym. Mater. 2019, 1, 885-892. [CrossRef]

17. Chen, Q.; Cao, P.; Advincula, R.C. Mechanically Robust, Ultraelastic Hierarchical Foam with Tunable Properties via 3D Printing. Adv. Funct. Mater. 2018, 28, 1800631. [CrossRef]

18. Espera, A.H., Jr.; Valino, A.D.; Palaganas, J.O.; Souz, L.; Chen, Q.; Advincula, R.C. 3D Printing of a Robust Polyam-ide-12-Carbon Black Composite via Selective Laser Sintering: Thermal and Electrical Conductivity. Macromol. Mater. Eng. 2019, $304,1800718$. [CrossRef]

19. Chen, Q.; Zhao, J.; Ren, J.; Rong, L.; Cao, P.; Advincula, R.C. 3D Printed Multifunctional, Hyperelastic Silicone Rubber Foam. Adv. Funct. Mater. 2019, 29, 1900469. [CrossRef]

20. Cabibihan, J.-J.; Javed, H.; Ang, M.; Aljunied, S.M. Why Robots? A Survey on the Roles and Benefits of Social Robots in the Therapy of Children with Autism. Int. J. Soc. Robot. 2013, 5, 593-618. [CrossRef]

21. Edin, B.; Beccai, L.; Ascari, L.; Roccella, S.; Cabibihan, J.; Carrozza, M. Bio-inspired approach for the design and characterization of a tactile sensory system for a cybernetic prosthetic hand. In Proceedings of the 2006 IEEE International Conference on Robotics Automation, Orlando, FL, USA, 15-19 May 2006. [CrossRef]

22. Tijing, L.; Dizon, J.R.; Cruz, G., Jr. 3D-Printed Absorbers for Solar-Driven Interfacial Water Evaporation: A Mini-Review. Adv. Sustain. Sci. Eng. Technol. 2021, 3, 0210103. [CrossRef]

23. Andres, N.S. Development of Solar-Powered Water Pump with 3D Printed Impeller. Open Eng. 2021, 11, 249-253. [CrossRef]

24. Siciliano, B.; Khatib, O. Springer Handbook of Robotics, 2nd ed.; Springer International Publishing: Berlin/Heidelberg, Germany, 2016; pp. 2522-8692.

25. Sirlantzis, K.; Larsen, L.B.; Kanumuru, L.K.; Oprea, P. Robotics Handbook of Electronic Assistive Technology; Academic Press: Cambridge, UK, 2019; pp. 311-345.

26. Veruggio, G.; Robotica, S.; Italy, G. The EURON Roboethics Roadmap. In Proceedings of the 6th IEEE-RAS International Conference on Humanoid Robots, Genova, Italy, 4-6 December 2006; pp. 612-617. [CrossRef]

27. Yirmibeşoğlu, O.D.; Oshiro, T.; Olson, G.; Palmer, C.; Mengüç, Y. Evaluation of 3D Printed Soft Robots in Radiation Environments and Comparison with Molded Counterparts. Front. Robot. AI 2019, 6. [CrossRef]

28. Roccella, S.; Carrozza, M.; Cappiello, G.; Zecca, M.; Miwa, H.; Ltoh, K.; Matsumoto, M.; Dario, P.; Cabibihan, J.; Takanishi, A. Design, fabrication and preliminary results of a novel anthropomorphic hand for humanoid robotics: RCH-1. In Proceedings of the International Confernce on Intelligent Robots and Systems (IROS), Sendai, Japan, 28 September-2 October 2004; pp. 266-271. [CrossRef]

29. Carrico, J.D.; Kim, K.J.; Leang, K.K. 3D-printed ionic polymer-metal composite soft crawling robot. In Proceedings of the IEEE International Conference on Robotics Automation (ICRA), Singapore, 29 May-3 June 2017; pp. 4313-4320. [CrossRef]

30. Bodkhe, S.; Ermanni, P. 3D printing of multifunctional materials for sensing and actuation: Merging piezoelectricity with shape memory. Eur. Polym. J. 2020, 132, 109738. [CrossRef]

31. Yuan, C.; Wang, F.; Qi, B.; Ding, Z.; Rosen, D.W.; Ge, Q. 3D printing of multi-material composites with tunable shape memory behavior. Mater. Des. 2020, 193, 108785. [CrossRef]

32. De Leon, A.C.; Rodier, B.J.; Bajamundi, C.; Espera, A.; Wei, P.; Kwon, J.G.; Williams, J.; Ilijasic, F.; Advincula, R.C.; Pentzer, E. Plastic Metal-Free Electric Motor by 3D Printing of Graphene-Polyamide Powder. ACS Appl. Energy Mater. 2018, 1, 1726-1733. [CrossRef]

33. Gul, J.Z.; Yang, B.-S.; Yang, Y.J.; Chang, D.E.; Choi, K.H. In situUV curable 3D printing of multi-material tri-legged soft bot with spider mimicked multi-step forward dynamic gait. Smart Mater. Struct. 2016, 25, 115009. [CrossRef]

34. Gul, J.Z.; Yang, Y.J.; Su, K.Y.; Choi, K.H. Omni Directional Multimaterial Soft Cylindrical Actuator and Its Application as a Steerable Catheter. Soft Robot. 2017, 4, 224-240. [CrossRef] [PubMed]

35. Edin, B.B.; Ascari, L.; Beccai, L.; Roccella, S.; Cabibihan, J.J.; Carrozza, M.C. Bio-inspired sensorization of a bio-mechatronic robot hand for the grasp-and-lift task. Brain Res. Bull. 2008, 75, 785-795. [CrossRef]

36. Wallin, T.J.; Pikul, J.; Shepherd, R.F. 3D printing of soft robotic systems. Nat. Rev. Mater. 2018, 3, 84-100. [CrossRef] 
37. Desai, J.P.; Sheng, J.; Cheng, S.S.; Wang, X.; Deaton, N.J.; Rahman, N. Toward Patient-Specific 3D-Printed Robotic Systems for Surgical Interventions. IEEE Trans. Med Robot. Bionics 2019, 1, 77-87. [CrossRef]

38. Diego, J.-R.R.; Martinez, D.W.C.; Robles, G.S.; Dizon, J.R.C. Development of Smartphone-Controlled Hand and Arm Exoskeleton for Persons with Disability. Open Eng. 2020, 11, 161-170. [CrossRef]

39. Tudela, A.J.; Ballesteros, J.; Bandera, A. Design and Implementation of a Low Cost 3D Printed Adaptive Hand. In Proceedings of the 19th International Workshop of Physical Agents, Madrid, Spain, 22-23 November 2018; pp. 271-283. [CrossRef]

40. Dizon, J.R.C.; Chen, Q.; Valino, A.D.; Advincula, R.C. Thermo-mechanical and swelling properties of three-dimensional-printed poly (ethylene glycol) diacrylate/silica nanocomposites. MRS Commun. 2019, 9, 209-217. [CrossRef]

41. Bandyopadhyay, A.; Heer, B. Additive manufacturing of multi-material structures. Mater. Sci. Eng. R Rep. 2018, 129, 1-16. [CrossRef]

42. Bhushan, B.; Caspers, M. An overview of additive manufacturing (3D printing) for microfabrication. Microsyst. Technol. 2017, 23, 1117-1124. [CrossRef]

43. Whisnant, D. Polymer Chemistry: Classification of Polymers. Available online: https://eng.libretexts.org/Bookshelves/ Materials_Science/Supplemental_Modules_(Materi-als_Science)/Polymer_Chemistry/Polymer_Chemistry\%3A_Morphology/ Polymer_Chemistry\%3A_Classification_of_Polymers (accessed on 8 September 2021).

44. Weidner, S.M. Mass Spectrometry: MALDI (Matrix-Assisted Laser Desorption/Ionization) and ESI (Electrospray Ionization). Fed. Inst. Mater. Res. Test. (BAM) 2012, 2, 93-109.

45. Carraher, C.E., Jr. Seymour/Carragher's Polymer Chemistry, 7th ed.; CRC Press: Boca Raton, FL, USA, 2007 ; Volume 14.

46. Kutz, M. Applied Plastics Engineering Handbook, 2nd ed.; William Andrew Publishing: Norwich, NY, USA, 2016 ; pp. 17-18.

47. Singh, R.; Kumar, R.; Farina, I.; Colangelo, F.; Feo, L.; Fraternali, F. Multi-material additive manufacturing of sustainable innovative materials and structures. Polymers 2019, 11, 62. [CrossRef] [PubMed]

48. Hamidi, A.; Tadesse, Y. 3D printing of very soft elastomer and sacrificial carbohydrate glass/elastomer structures for robotic applications. Mater. Des. 2019, 187, 108324. [CrossRef]

49. Singh, R.; Singh, S. Additive Manufacturing: An Overview. Ref. Modul. Mater. Sci. Mater. Eng. 2017, 1, 1-12.

50. Campbell, T.; Williams, C.; Ivanova, O.; Garrett, B. Strategic Foresight Report. Atl. Counc. 2014, 3-7.

51. Bikas, H.; Stavropoulos, P.; Chryssolouris, G. Additive manufacturing methods and modelling approaches: A critical review. Int. J. Adv. Manuf. Technol. 2015, 83, 389-405. [CrossRef]

52. Horn, T.J.; Harrysson, O.L.A. Overview of Current Additive Manufacturing Technologies and Selected Applications. Sci. Prog. 2012, 95, 255-282. [CrossRef] [PubMed]

53. Standard ISO/ASTM 52900 Additive Manufacturing-General Principles-Terminology. Available online: https://www.iso.org/ obp/ui/\#iso:std:iso-astm:52900:ed-1:v1:en (accessed on 23 August 2020).

54. Lee, J.-Y.; An, J.; Chua, C.K. Fundamentals and applications of 3D printing for novel materials. Appl. Mater. Today 2017,7 , 120-133. [CrossRef]

55. Geng, H. Manufacturing Engineering Handbook, 2nd ed.; McGraw-Hill Education: New York, NY, USA, 2016.

56. Gao, W.; Zhang, Y.; Ramanujan, D.; Ramani, K.; Chen, Y.; Williams, C.; Wang, C.C.; Shin, Y.C.; Zhang, S.; Zavattieri, P. The status, challenges, and future of additive manufacturing in engineering. Comput. Des. 2015, 69, 65-89. [CrossRef]

57. Introduction to 3D Printing-Additive Processes. Available online: https://make.3dexperience.3ds.com/processes/3D-printing (accessed on 17 July 2020).

58. Diegel, A.O.; Nordin; Motte, D. Additive Manufacturing Technologies; Springer: Singapore, 2019.

59. Our Technology-Carbon3D. Available online: https://www.carbon3d.com/3d-printer-models-carbon/our-technology / (accessed on 24 July 2020).

60. Hildebrand, K.; Bickel, B.; Alexa, M. Orthogonal slicing for additive manufacturing. Comput. Graph. 2013, 37, 669-675. [CrossRef]

61. Vitale, M.; Cotteleer, M.; Holdowsky, J. An Overview of Additive Manufacturing. Available online: https://medium.com/ @DAUNow / an-introduction-to-additive-manufacturing-7c468d099f2c (accessed on 4 November 2016).

62. Crampton, L. CLIP 3D Printing Technology: Objects Created in Liquid Resin. Available online: https://turbofuture.com/ industrial/New-3D-Printing-Technology-Objects-Grow-From-a-Pool-of-Liquid (accessed on 24 July 2020).

63. Batcha, S.; Sadik Batcha, M. Research Output Analysis on Robotic Technology: A Scientometric Study Library Management View project Research Output Analysis on Robotic Technology: A Scientometric Study. Indian J. Inf. Sources Serv. $2017,7,25-31$.

64. Chen, A.; Yin, R.; Cao, L.; Yuan, C.; Ding, H.; Zhang, W. Soft robotics: Definition and research issues. In Proceedings of the 24th International Conference on Mechatronics and Machine Vision Practice (M2VIP), Auckland, New Zealand, 21-23 November 2017; pp. 366-370. [CrossRef]

65. Signorelli, C.M. Can Computers Become Conscious and Overcome Humans? Front. Robot. AI 2018, 5. [CrossRef] [PubMed]

66. Kim, S.; Laschi, C.; Trimmer, B. Soft robotics: A bioinspired evolution in robotics. Trends Biotechnol. 2013, 31, 287-294. [CrossRef] [PubMed]

67. Rus, D.; Tolley, M.T. Design, fabrication and control of soft robots. Nature 2015, 521, 467-475. [CrossRef] [PubMed]

68. Kastor, N.; Vikas, V.; Cohen, E.; White, R.D. A Definition of Soft Materials for Use in the Design of Robots. Soft Robot. 2017, 4, 181-182. [CrossRef] [PubMed]

69. Chen, C.; Tang, Y.; Wang, H.; Wang, Y. A review of fabrication options and power electronics for flapping-wing robotic insects. Int. J. Adv. Robot. Syst. 2013, 10, 779-786. [CrossRef] 
70. Rubio, F.; Valero, F.; Llopis-Albert, C. A review of mobile robots: Concepts, methods, theoretical framework, and applications. Int. J. Adv. Robot. Syst. 2019, 16, 1729881419839596. [CrossRef]

71. Shanmugavel, B. Applications and Future scope of Robotics-A Review. Int. J. Robot. Auton. Syst. 2018, 3, 12-26.

72. Park, I.W.; Kim, J.Y.; Lee, J.; Oh, J.H. Mechanical design of humanoid robot platform KHR-3 (KAIST humanoid robot-3: HUBO). In Proceedings of the 2005 5th IEEE-RAS International Conference on Humanoid Robots, Tsukuba, Japan, 5 December 2005. [CrossRef]

73. Li, P.; Liu, X. Common Sensors in Industrial Robots: A Review. J. Physics Conf. Ser. 2019, 1267. [CrossRef]

74. Harashima, F. Sensor based robot control systems. In Proceedings of the 1990 IEEE Colloquium in South America COLLOQ, Argentina, Brazil, Chile, Uruguay, 31 August-15 September 1990; pp. 203-208.

75. Zaki, A.M.; Arafa, O.; Amer, S.I. Microcontroller-based mobile robot positioning and obstacle avoidance. J. Electr. Syst. Inf. Technol. 2014, 1, 58-71. [CrossRef]

76. Bouchard, S. Industrial Robots: What Are the Different Types? Available online: https://blog.robotiq.com/bid/63528/what-arethe-different-types-of-industrial-robots (accessed on 13 March 2014).

77. Anish, B. Application of Robotics in Manufacturing. J. Emerg. Technol. Innov. Res. 2019, 251-260.

78. Mohammed, S.; Fiaidh, J. Cyber Physical Systems: A New Frontier of Artificial Intelligence: Summary Paper. Int. J. Control. Autom. 2019, 12, 23-30. [CrossRef]

79. Gonzalez, C. What's the Difference Between Industrial Robots? Available online: https://www.machinedesign.com/markets/ robotics/article/21835000/whats-the-difference-between-industrial-robots (accessed on 2 December 2016).

80. Vargas, S. Robots in the Workplace. Safety Health, 25 March 2018.

81. Sprynn, M. What Material Should I Use for My Robotic Chassis? Available online: http://www.mitchellspryn.com/2017/06/04 /What-Material-Should-I-Use-For-My-Robotic-Chassis.html (accessed on 18 January 2021).

82. Stamp, B.J. The Robot Revolution Is for the Birds. Look up for Robotic Ravens and Cyborg Pigeons. Smithsonian Magazine, 24 May 2013.

83. Wild, F. What Is Robonaut? Available online: https://www.nasa.gov/audience/forstudents/k-4/stories/nasa-knows/what-isrobonaut-k4.html (accessed on 18 January 2021).

84. Mann, A. The Mars Rovers. Available online: https:/ /www.space.com/mars-rovers.html (accessed on 18 January 2021).

85. Kardasz, P.; Doskocz, J. Drones and Possibilities of Their Using. J. Civ. Environ. Eng. 2016, 6. [CrossRef]

86. Crawford, M. Top 6 Robotic Applications in Medicine. Available online: https://www.asme.org/topics-resources/content/top6-robotic-applications-in-medicine (accessed on 18 January 2021).

87. Ben-Ari, M.; Mondada, F. Robots and Their Applications. Elem. Robot. 2018, 1-20. [CrossRef]

88. Robotics Industries Association. Robotics in Agriculture: Types and Applications; A3 Association for Advancing Automation: Ann Arbor, MI, USA, 2017.

89. Mubin, O.; Stevens, C.J.; Shahid, S.; Al Mahmud, A.; Dong, J.-J. A Review of the Applicability of Robots in Education. Technol. Educ. Learn. 2013, 1. [CrossRef]

90. Stasse, O.; Flayols, T. An Overview of Humanoid Robots Technologies. Springer Tracts Adv. Robot 2019, 124, 281-310. [CrossRef]

91. Pakdaman, M.; Sanaatiyan, M.M.; Ghahroudi, M.R. A line follower robot from design to implementation: Technical issues and problems. In Proceedings of the 2nd International Conference on Computer and Automation Engineering, Singapore, 26-28 February 2010; pp. 5-9. [CrossRef]

92. Components of Robots. Available online: https://www.javatpoint.com/components-of-robot (accessed on 19 December 2020).

93. Trivedi, D.; Rahn, C.D.; Kier, W.M.; Walker, I.D. Soft robotics: Biological inspiration, state of the art, and future research. Appl. Bionics Biomech. 2008, 5, 99-117. [CrossRef]

94. Schmitt, F.; Piccin, O.; Barbé, L.; Bayle, B. Soft Robots Manufacturing: A Review. Front. Robot. AI 2018, 5. [CrossRef] [PubMed]

95. Iida, F.; Laschi, C. Soft Robotics: Challenges and Perspectives. Proc. Comput. Sci. 2011, 7, 99-102. [CrossRef]

96. Srivastava, S. Soft Robotics vs. Hard Robotics: How Are They Different? Available online: https://www.analyticsinsight.net/ soft-robotics-vs-hard-robotics-different/ (accessed on 9 July 2020).

97. University of California. Embedded Systems-Develop and Implement Embedded Systems. Available online: https: / / extension.ucsd.edu/courses-and-programs/embedded-engineering?fbclid=IwAR2bS_Et56844HLnTBYqjcVKoBzphacz5 hH9Z2o9AIzOgZzhYQughJlJoaA (accessed on 18 March 2021).

98. Bräunl, T. Embedded Robotics: Mobile Robot Design and Applications with Embedded Systems; Springer: Berlin/Heidelberg, Germany, 2006.

99. Gaud, N. A critical analysis of scientific productivity of the 'robotics' research in India during 2009-2018. Libr. Philos. Pract. 2019, 2345.

100. Yuncheng, S. Research on Modeling and Design of Real-Time Embedded Systems. In Proceedings of the 7th International Conference on Intelligent Computation Technology and Automation (ICICTA), Changsha, China, 25-26 October 2014; pp. 547-550. [CrossRef]

101. Thornton, S. Overview of Embedded Systems. Available online: https:/ /www.microcontrollertips.com/faq-overview-embeddedsystems/?fbclid=IwAR0nfij3m8FGVnNleRDpZ-WZe4cOkb1eFDJ5K105fdJfAISBOTUE_1_Vyo8 (accessed on 18 March 2021).

102. Joyee, E.B.; Pan, Y. A Fully Three-Dimensional Printed Inchworm-Inspired Soft Robot with Magnetic Actuation. Soft Robot. 2019, 6, 333-345. [CrossRef] [PubMed] 
103. Karakurt, I.; Lin, L. 3D printing technologies: Techniques, materials, and post-processing. Curr. Opin. Chem. Eng. 2020, 28, 134-143. [CrossRef]

104. Shi, I.; Dagalakis, N.; Kim, Y.; Duan, X. A 3D printing flexure pressure sensor for robot impact safety testing. In Proceedings of the 5th Asia International Symposium on Mechatronics (AISM 2015), Guilin, China, 7-10 October 2015.

105. Zolfagharian, A.; Kaynak, A.; Kouzani, A. Closed-loop 4D-printed soft robots. Mater. Des. 2019, 188, 108411. [CrossRef]

106. Al-Rubaiai, M.; Pinto, T.; Qian, C.; Tan, X. Soft Actuators with Stiffness and Shape Modulation Using 3D-Printed Conductive Polylactic Acid Material. Soft Robot. 2019, 6, 318-332. [CrossRef] [PubMed]

107. Lee, C.; Myungjoon, K.; Kim, Y.J.; Hong, N.; Ryu, S.; Kim, H.J.; Kim, S. Soft Robot Review. Int. J. Control. Autom. Syst. 2017, 1-13. [CrossRef]

108. Song, S.-H.; Ahn, S.-H.; Park, C.H.; Son, Y.S. Design of soft actuator using 3D-printed composite. In Proceedings of the 14th International Conference Ubiquitous Robot Ambient Intelligence (URAI), Jeju, Korea, 28 June-1 July 2017; pp. 79-80. [CrossRef]

109. Pearson, A. Wired's 400-Pound Comic-con Robot Has a 3D Printed Face. Available online: https://www.stratasys.com/de/ explore/blog/2014/comic-con-3d-printed-robot-legacy-effects (accessed on 19 December 2020).

110. Yap, H.K.; Ng, H.Y.; Yeow, C.-H. High-Force Soft Printable Pneumatics for Soft Robotic Applications. Soft Robot. 2016, 3, 144-158. [CrossRef]

111. Lifton, V.A.; Lifton, G.; Simon, S. Options for additive rapid prototyping methods (3D printing) in MEMS technology. Rapid Prototyp. J. 2014, 20, 403-412. [CrossRef]

112. Stratasys. Form Automation Relies on the Stratasys F370 3D Printer for End-of-Arm Tooling. Available online: https://www. stratasys.com/explore/case-study/form-automation (accessed on 27 November 2020).

113. Wolterink, G.; Sanders, R.; Muijzer, F.; Van Beijnum, B.-J.; Krijnen, G.J. 3D-printing soft sEMG sensing structures. Proc. IEEE Sens. 2017, 2017, 1-3. [CrossRef]

114. Scharff, R.B.N.; Doubrovski, E.L.; Poelman, W.A.; Jonker, P.P.; Wang, C.C.L.; Geraedts, J.M.P. Towards Behavior Design of a 3D-Printed Soft Robotic Hand. In Soft Robotics: Trends, Applications and Challenges; Springer: Cham, Switzerland, 2016 ; pp. 23-29.

115. Truby, R.; Lewis, J.A. Printing soft matter in three dimensions. Nature 2016, 540, 371-378. [CrossRef]

116. Roppenecker, D.B.; Pfaff, A.; Coy, J.A.; Lueth, T.C. Multi arm snake-like robot kinematics. In Proceedings of the International Conference on Intelligent Robots and Systems, Tokyo, Japan, 3-7 November 2013; pp. 5040-5045. [CrossRef]

117. Chan, V.; Park, K.; Collens, M.B.; Kong, H.; Saif, T.A.; Bashir, R. Development of Miniaturized Walking Biological Machines. Sci. Rep. 2012, 2, srep00857. [CrossRef]

118. Warner, J.; Soman, P.; Zhu, W.; Tom, M.; Chen, S. Design and 3D Printing of Hydrogel Scaffolds with Fractal Geometries. ACS Biomater. Sci. Eng. 2016, 2, 1763-1770. [CrossRef] [PubMed]

119. Peele, B.N.; Wallin, T.J.; Zhao, H.; Shepherd, R. 3D printing antagonistic systems of artificial muscle using projection stereolithography. Bioinspiration Biomim. 2015, 10, 055003. [CrossRef]

120. Tian, L.; Liu, J.; Thalmann, N.M.; Thalmann, D.; Zheng, J. Design of a Flexible Articulated Robotic Hand for a Humanoid Robot. In Proceedings of the RAS 19th International Conference on Humanoid Robots, Toronto, ON, Canada, 15-17 October 2019; pp. 572-577. [CrossRef]

121. Martinez, R.; Branch, J.L.; Fish, C.R.; Jin, L.; Shepherd, R.; Nunes, R.M.D.; Suo, Z.; Whitesides, G.M. Robotic Tentacles with Three-Dimensional Mobility Based on Flexible Elastomers. Adv. Mater. 2012, 25, 205-212. [CrossRef]

122. Shih, B.; Christianson, C.; Gillespie, K.; Lee, S.; Mayeda, J.; Huo, Z.; Tolley, M.T. Design Considerations for 3D Printed, Soft, Multimaterial Resistive Sensors for Soft Robotics. Front. Robot. AI 2019, 6. [CrossRef]

123. MacCurdy, R.; Katzschmann, R.; Kim, Y.; Rus, D. Printable hydraulics: A method for fabricating robots by 3D co-printing solids and liquids. In Proceedings of the IEEE International Conference on Robotics and Automation, Stockholm, Sweden, 16-21 May 2016; pp. 3878-3885. [CrossRef]

124. Wimpenny, D.I.; Pandey, P.M.; Kumar, J. Advances in 3D Printing \& Additive Manufacturing Technologies; Springer: Singapore, 2017.

125. Drotman, D.; Jadhav, S.; Karimi, M.; de Zonia, P.; Tolley, M.T. 3D printed soft actuators for a legged robot capable of navigating unstructured terrain. In Proceedings of the IEEE International Conference on Robotics and Automation, Singapore, 29 May-3 June 2017; pp. 5532-5538. [CrossRef]

126. Kalisky, T.; Wang, Y.; Shih, B.; Drotman, D.; Jadhav, S.; Aronoff-Spencer, E.; Tolley, M.T. Differential pressure control of 3D printed soft fluidic actuators. In Proceedings of the IEEE International Conference on Intelligent Robots and Systems, Vancouver, BC, Canada, 24-28 September 2017; pp. 6207-6213. [CrossRef]

127. Pearson, A. 3D Printed Robotic Gripper: Smarter Design, Faster Delivery, Better Value for Customer, Stratasys Blog. Available online: https:/ / www.stratasys.com/explore/blog/2014/3d-printing-digital-mechanics (accessed on 9 July 2020).

128. Zhang, Y.; Ng, C.J.; Chen, Z.; Zhang, W.; Panjwani, S.; Kowsari, K.; Yang, H.Y.; Ge, Q. Miniature Pneumatic Actuators for Soft Robots by High-Resolution Multimaterial 3D Printing. Adv. Mater. Technol. 2019, 4, 1900427. [CrossRef]

129. Robinson, S.S.; O’Brien, K.W.; Zhao, H.; Peele, B.N.; Larson, C.M.; Mac Murray, B.; Van Meerbeek, I.M.; Dunham, S.; Shepherd, R. Integrated soft sensors and elastomeric actuators for tactile machines with kinesthetic sense. Extreme Mech. Lett. 2015, 5, 47-53. [CrossRef]

130. Joyee, E.B.; Pan, Y. Multi-material Additive Manufacturing of Functional Soft Robot. Proc. Manuf. 2019, 34, 566-573. [CrossRef] 
131. Xu, X.; Cheng, W.; Dudek, D.; Hatanaka, M.; Cutkosky, M.R.; Full, R.J. Material Modeling for Shape Deposition Manufacturing of Biomimetic Components. In Proceedings of the International Design Engineering Technical Conferences and Computers and Information in Engineering Conference, Baltimore, MD, USA, 10-13 September 2000; pp. 205-214. [CrossRef]

132. Bailey, S.A.; Cham, J.G.; Cutkosky, M.R.; Full, R.J. Biomimetic Robotic Mechanisms via Shape Deposition Manufacturing. Robot. Res. 2000, 403-410. [CrossRef]

133. Dollar, A.M.; Howe, R.D. Design and Evaluation of a Robust Compliant Grasper Using Shape Deposition Manufacturing. Am. Soc. Mech. Eng. Dyn. Syst. Control Div. DSC 2005, 74, 1403-1410. [CrossRef]

134. Cham, J.G.; Bailey, S.A.; Clark, J.E.; Full, R.J.; Cutkosky, M.R. Fast and Robust: Hexapedal Robots via Shape Deposition Manufacturing. Int. J. Robot. Res. 2002, 21, 869-882. [CrossRef]

135. Gafford, J.; Ding, Y.; Harris, A.; McKenna, T.; Polygerinos, P.; Holland, D.; Walsh, C.; Moser, A. Shape Deposition Manufacturing of a Soft, Atraumatic, and Deployable Surgical Grasper. J. Mech. Robot. 2015, 7, 021006. [CrossRef]

136. Mousavi, S.; Howard, D.; Wu, S.; Wang, C. An Ultrasensitive 3D Printed Tactile Sensor for Soft Robotics. arXiv 2018, arXiv:1810.09236.

137. Wolterink, G.; Dias, P.; Sanders, R.G.P.; Muijzer, F.; Van Beijnum, B.-J.; Veltink, P.; Krijnen, G. Development of Soft sEMG Sensing Structures Using 3D-Printing Technologies. Sensors 2020, 20, 4292. [CrossRef]

138. Shih, B.; Mayeda, J.; Huo, Z.; Christianson, C.; Tolley, M.T. 3D printed resistive soft sensors. In Proceedings of the IEEE International Conference on Soft Robotics (RoboSoft), Livorno, Italy, 24-28 April 2018; pp. 152-157. [CrossRef]

139. Yirmibesoglu, O.D.; Morrow, J.; Walker, S.; Gosrich, W.; Canizares, R.; Kim, H.; Daalkhaijav, U.; Fleming, C.; Branyan, C.; Menguc, Y. Direct 3D printing of silicone elastomer soft robots and their performance comparison with molded counterparts. In Proceedings of the IEEE International Conference on Soft Robotics (RoboSoft), Livorno, Italy, 24-28 April 2018 ; pp. $295-302$. [CrossRef]

140. Joyee, E.B.; Pan, Y. Additive manufacturing of multi-material soft robot for on-demand drug delivery applications. J. Manuf. Process. 2020, 56, 1178-1184. [CrossRef]

141. Joyee, E.B.; Lu, L.; Pan, Y. Analysis of mechanical behavior of 3D printed heterogeneous particle-polymer composites. Compos. Part B Eng. 2019, 173, 106840. [CrossRef]

142. Lu, L.; Tang, X.; Hu, S.; Pan, Y. Acoustic Field-Assisted Particle Patterning for Smart Polymer Composite Fabrication in Stereolithography. 3D Print. Addit. Manuf. 2018, 5, 151-159. [CrossRef]

143. Fretty, P. 2020: Future of Manufacturing Technology. Available online: https://www.industryweek.com/technology-and-iiot/ article/22028667/2020-future-of-manufacturing-technology (accessed on 3 August 2020).

144. Dizon, J.R.C.; Gache, C.C.L.; Cascolan, H.M.S.; Cancino, L.T.; Advincula, R.C. Post-Processing of 3D-Printed Polymers. Technologies 2021, 9, 61. [CrossRef]

145. Hann, S.Y.; Cui, H.; Nowicki, M.; Zhang, L.G. 4D printing soft robotics for biomedical applications. Addit. Manuf. 2020, $36,101567$. [CrossRef]

146. Song, Y.S.; Sun, Y.; Brand, R.V.D.; Von Zitzewitz, J.; Micera, S.; Courtine, G.; Paik, J. Soft robot for gait rehabilitation of spinalized rodents. In Proceedings of the International Conference on Intelligent Robots and Systems, Tokyo, Japan, 3-7 November 2013; pp. 971-976. [CrossRef]

147. Joshi, S.; Rawat, K.; Karunakaran, C.; Rajamohan, V.; Mathew, A.T.; Koziol, K.; Thakur, V.K.; Balan, A.S.S. 4D printing of materials for the future: Opportunities and challenges. Appl. Mater. Today 2019, 18, 100490. [CrossRef]

148. Lee, J.-Y.; Tan, W.S.; An, J.; Chua, C.K.; Tang, C.Y.; Fane, A.G.; Chong, T.H. The potential to enhance membrane module design with 3D printing technology. J. Membr. Sci. 2016, 499, 480-490. [CrossRef]

149. Huang, B.; Hu, R.; Xue, Z.; Zhao, J.; Li, Q.; Xia, T.; Zhang, W.; Lu, C. Continuous liquid interface production of alginate/polyacrylamide hydrogels with supramolecular shape memory properties. Carbohydr. Polym. 2019, 231, 115736. [CrossRef] [PubMed]

150. Thakur, S.; Hu, J. Polyurethane: A Shape Memory Polymer (SMP). In Aspects of Polyurethanes; IntechOpen: London, UK, 2017.

151. Song, J.J.; Srivastava, I.; Kowalski, J.; Naguib, H.E. Fabrication and characterization of a foamed polylactic acid (PLA)/thermoplastic polyurethane (TPU) shape memory polymer (SMP) blend for biomedical and clinical applications. Behav. Mech. Multifunct. Mater. Compos. 2014, 9058, 90580B. [CrossRef]

152. Grzesiak, J.; Marycz, K.; Szarek, D.; Bednarz, P.; Laska, J. Polyurethane/polylactide-based biomaterials combined with rat olfactory bulb-derived glial cells and adipose-derived mesenchymal stromal cells for neural regenerative medicine applications. Mater. Sci. Eng. C 2015, 52, 163-170. [CrossRef]

153. Mi, H.-Y.; Salick, M.R.; Jing, X.; Jacques, B.R.; Crone, W.C.; Peng, X.-F.; Turng, L.-S. Characterization of thermoplastic polyurethane/polylactic acid (TPU/PLA) tissue engineering scaffolds fabricated by microcellular injection molding. Mater. Sci. Eng. C 2013, 33, 4767-4776. [CrossRef]

154. Bekas, D.; Hou, Y.; Liu, Y.; Panesar, A. 3D printing to enable multifunctionality in polymer-based composites: A review. Compos. Part B Eng. 2019, 179. [CrossRef]

155. Oliaei, E.; Kaffashi, B. Investigation on the properties of poly(l-lactide)/thermoplastic poly (ester urethane)/halloysite nanotube composites prepared based on prediction of halloysite nanotube location by measuring free surface energies. Polymer 2016, 104, 104-114. [CrossRef] 
156. Song, J.J.; Chang, H.H.; Naguib, H.E. Design and characterization of biocompatible shape memory polymer (SMP) blend foams with a dynamic porous structure. Polymer 2015, 56, 82-92. [CrossRef]

157. Oliaei, E.; Kaffashi, B.; Davoodi, S. Investigation of structure and mechanical properties of toughened poly(l-lactide)/thermoplastic poly(ester urethane) blends. J. Appl. Polym. Sci. 2015, 133. [CrossRef]

158. Macdonald, N.P.; Zhu, F.; Hall, C.J.; Reboud, J.; Crosier, P.S.; Patton, E.E.; Wlodkowic, D.; Cooper, J.M. Assessment of biocompatibility of 3D printed photopolymers using zebrafish embryo toxicity assays. Lab Chip 2015, 16, 291-297. [CrossRef] [PubMed]

159. Alifui-Segbaya, F.; Varma, S.; Lieschke, G.J.; George, R. Biocompatibility of Photopolymers in 3D Printing. 3D Print. Addit. Manuf. 2017, 4, 185-191. [CrossRef]

160. Kelly, B.E.; Bhattacharya, I.; Heidari, H.; Shusteff, M.; Spadaccini, C.M.; Taylor, H.K. Volumetric additive manufacturing via tomographic reconstruction. Science 2019, 363, 1075-1079. [CrossRef] [PubMed]

161. Manke, K. New 3D printer uses rays of light to shape objects, transform product design. Available online: https:/ / news.berkeley. edu/2019/01/31/new-3d-printer-uses-rays-of-light-to-shape-objects-transform-product-design/ (accessed on 31 January 2019)

162. Spencer, L. 3D Printing Filament Shrinkage Compensation. Available online: https://3dknowledge.com/3d-printing-shrinkagecompensation/ (accessed on 13 August 2020).

163. Redwood, B. Dimensional accuracy of 3D printed parts. Available online: https:/ / www.hubs.com/knowledge-base/dimensionalaccuracy-3d-printed-parts/\#fdm (accessed on 12 October 2021).

164. Redwood, B. How does part orientation affect a 3D print? Available online: https://www.hubs.com/knowledge-base/howdoes-part-orientation-affect-3d-print/ (accessed on 12 October 2021).

165. Formlabs. Validating Isotropy in SLA 3D Printing. Available online: https://formlabs.com/asia/blog/isotropy-in-SLA-3Dprinting/ (accessed on 12 October 2021).

166. Monzón, M.; Ortega, Z.; Hernández, A.; Paz, R.; Ortega, F. Anisotropy of Photopolymer Parts Made by Digital Light Processing. Materials 2017, 10, 64. [CrossRef] [PubMed] 